DOE/NASA/0335-6

NASA CR-195393

AlliedSignal 31-12089

\title{
ADVANCED TURBINE TECHNOLOGY APPLICATIONS PROJECT (ATTAP) 1993 ANNUAL REPORT
}

Engineering Staff of

AlliedSignal Engines, Phoenix, Arizona

A Unit of AlliedSignal Aerospace Company

July 1994

Prepared for

NATIONAL AERONAUTICS AND SPACE ADMINISTRATION

Lewis Research Center

Cleveland, Ohio 44135

Under Contract DEN3-335

For

U.S. DEPARTMENT OF ENERGY

Office of Transportation Technologies

Advanced Propulsion Division

Washington, D.C. 20585

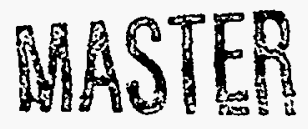

DISTRIBUTION OF THIS DOCUMENT IS UNLIMITED 


\section{DISCLAIMER}

Portions of this document may be illegible in electronic image products. Images are produced from the best available original document. 


\section{Disclaimer}

This report was prepared as an account of work sponsored by an agency of the United States Government. Neither the United States Government nor any agency thereof, nor any of their employees, makes any warranty, express or implied, or assumes any legal liability or responsibility for the accuracy, completeness, or usefulness of any information, apparatus, product or process disclosed, or represents that its use would not infringe privately owned rights. Reference herein to any specified commercial product, process, or service by trade name, trademark, manufacturer, or otherwise, does not necessarily constitute or imply its endorsement, recommendation, or favoring by the United States Government or any agency thereof. The views and opinions of authors expressed herein do not necessarily state or reflect those of the United States Government or any agency thereof.

Printed in the United States of America

Available from:

National Technical Information Service

U.S. Department of Commerce

5285 Port Royal Road

Springfield, VA 212161

NTIS Price Codes:

Printed Copy: A04

Microfiche Copy: A01

1 Codes are used for pricing all publications. The code is determined by the number of pages in the publication. Information pertaining to the pricing codes can be found in the current issues of the following publications, which are generally available in most libraries: Energy Research Abstracts (ERA); Government Reports Announcements and Index (GRA and I); Scientific and Technical Abstract Reports (STAR); and publication, NTIS-PR-360 available from NTIS at the above address. 


\section{TABLE OF CONTENTS}

Page

1.0 SUMMARY 1

1.1 Design 1

1.2 Fabrication 1

1.3 Component Testing 2

1.4 Ceramic Technologies 2

1.5 Engine Testing 3

2.0 INTRODUCTION 4

3.0 TURBINE STAGE DESIGN, PRELIMINARY MODELING, AND ANALYSIS 6

3.1 Blade And Disk Design 6

3.1.1 Nozzle And Blade Aerodynamic Design 7

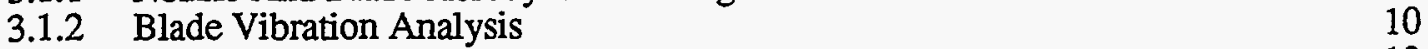

3.1.3 Blade Stress Analysis 13

3.1.4 Blade Axial Retention 13

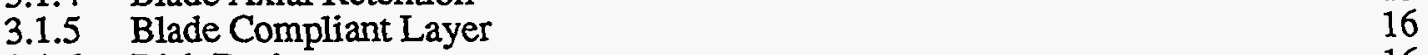

3.1.6 Disk Design 16

3.2 Nozzle Design And Analysis 16

3.3 Structure Design And Analysis 19

4.0 COMPONENT FABRICATION

$\begin{array}{lll}5.0 & \text { COMPONENT TESTING } & 26\end{array}$

5.1 Blade Component Testing 26

5.2 Blade And Rotor Proof Testing 26

5.3 Blade Airjet Impingement Testing 28

5.4 Nozzle Proof Testing $\quad 28$

6.0 CERAMIC TECHNOLOGIES AND METHODS 31

6.1 Ceramic Blade Attachment 31

6.2 NDE Reliability

6.3 Ceramic Oxidation And Hot Corrosion 34

6.4 Impact Design Methods 37

$\begin{array}{lll}7.0 & \text { ENGINE TESTING } & 38\end{array}$

7.1 Ceramic Nozzle Engine Testing 38

7.1.1 Engine Start Cycle Modifications 38

7.1.2 Ceramic Nozzle Operability Test 40

7.1.3 Accelerated Mission Cycle Test 40

7.2 Ceramic Blade Engine Testing $\quad 42$

8.0 PROGRAM MANAGEMENT 


\section{LIST OF FIGURES}

Figure

Title

Page

1 AlliedSignal/Garrett Model 331-200 APU Used As ATTAP Test Bed Engine Has Proven Capability For Long-Term Endurance Testing 4

2 ATTAP 331-200[CT] Ceramic Turbine Blades Installed In Metallic Rotor Disk

3 Three-Dimensional Inviscid Flow Analysis Results Show Acceptable Diffusion For ATTAP/331-200[CT] Ceramic Nozzle Design

4 Inviscid Flow Analysis Results For ATTAP/331-200[CT] Ceramic Turbine Blades Indicate: (a) Satisfactory Diffusion At Hub And Mid Span, And

(b) Typical Degraded Performance At The Blade Tip, Which May Be Corrected By Optimizing Tip Clearance

5 Campbell Diagram For Final ATTAP/331-200[CT] Ceramic Blade Airfoil Design Indicates Acceptable Vibration Frequency Margin

6 Ceramic Blade Stress Analysis Results Were Satisfactory 13

$7 \quad$ Ceramic Turbine Blade Attachment Geometry Was Optimized 14

8 ATTAP 331-200[CT] Axial Ceramic Blade Retention Scheme Employs A Bent Tab And Compliant Layer

9 Baseline ATTAP 331-200[CT] Ceramic Nozzle Design Was Completed In $1992 \quad 17$

10 Predicted Peak Temperature And Stress Values For ATTAP/331-200[CT] Ceramic Nozzle Occur During Engine Startup

11 ATTAP Ceramic Nozzle Redesign Efforts In 1993 Included Changes For Improved Manufacturability

12 ATTAP/331-200[CT] Structural Design Incorporates Features To Accommodate Ceramic Turbine Components

13 Initial Engine Test Results Indicated Excessive Cooling Air Leakage

14 Modifications To The Engine Outer Structure Were Accomplished, To Enhance Sealing And Reduce Thermal Deflections

15 Engine Structure Design Improvements Are Continuing

16 ATTAP/331-200[CT] Ceramic Turbine Blade (Norton Advanced Ceramics NT154 Silicon Nitride)

17 ATTAP/331-200[CT] Ceramic Nozzle Segment (AlliedSignal Ceramic Components GN-10 Silicon Nitride)

18 Ceramic Turbine Blades Are Qualified For Engine Testing In Whirlpit Test Rig 


\section{LIST OF FIGURES (Contd)}

19 Ceramic Nozzle Proof Test Rig Is Designed To Simulate Engine Stresses

20 Nozzle Proof Test Section Incorporates A Standard Machine Collet For Rapid Installation And Changeout Of Nozzle Segments

21 Ceramic Nozzle Proof Test Conditions Are More Severe Than Those Seen In Engine Operation

22 Ceramic Blade Attachment Specimen Testing Will Be Performed Using The Existing ATTAP Contact Test Rig

23 Hot Corrosion Attack Reduced Thickness Of NT154 Silicon Nitride Strength Test Specimens In Exposures Above 900C (1652F)

24 Mechanistic Model Predicts Environmental Life (Strength Retention) Of NT154 Silicon Nitride Exposed To Hot Corrosion Environment

25 Comparison Of Ceramic Environmental Life Model Predictions With Hot Corrosion Test Results Shows Surface Strength Reduction Is Sensitive To Exposure Time And Severity Of The Burner Rig Test Environment

26 Typical Silicon Nitride Component Environmental Life Plot For Selected Parameters

27 ATTAP/331-200[CT] Test Bed Engine Installed In The Test Cell

28 Ceramic Nozzle Assembly Was Undamaged Following Engine Testing

29 Localized Contact Areas Were Noted On Ceramic Blade Dovetail Following First Ceramic Blade Equipped Engine Test Failure

30 AlliedSignal ATTAP Leadership Team Utilizes Total Quality Leadership (TQL) Techniques To Coordinate Activities Of The Participating Engineering Technical Teams

311993 ATTAP/331-200 Ceramic Turbine Engine Demonstration Program Schedule Shows Tasks Planned And Completed 


\section{LIST OF TABLES}

Table

Title

Page

1 331-200[CT] CERAMIC TURBINE DESIGN CYCLE CONDITIONS

2 TURBINE BLADE ATTACHMENT SPECIMEN TEST MATRIX

32

3 OXIDATION AND HOT CORROSION EXPOSURE TEST CONDITIONS

34 


\section{ACRONYMS AND ABBREVIATIONS}

\begin{tabular}{|c|c|}
\hline $\begin{array}{l}\text { AGT } \\
\text { APU } \\
\text { ASME } \\
\text { atm } \\
\text { ATTAP } \\
\text { AZ }\end{array}$ & $\begin{array}{l}\text { Advanced Gas Turbine } \\
\text { Auxiliary Power Unit } \\
\text { American Society of Mechanical Engineers } \\
\text { Atmosphere } \\
\text { Advanced Turbine Technology Applications Project } \\
\text { Arizona }\end{array}$ \\
\hline $\begin{array}{l}\mathrm{C} \\
\mathrm{CA} \\
\mathrm{Ca} \\
\mathrm{CC} \\
\mathrm{CIP} \\
\mathrm{CT}\end{array}$ & $\begin{array}{l}\text { Celsius } \\
\text { California } \\
\text { Calcium } \\
\text { AlliedSignal Ceramic Components } \\
\text { Cold Isostatic Pressing } \\
\text { Connecticut }\end{array}$ \\
\hline $\begin{array}{l}\text { DARPA } \\
\text { deg } \\
\text { DOE }\end{array}$ & $\begin{array}{l}\text { Defense Advanced Research Projects Agency } \\
\text { Degrees } \\
\text { Department Of Energy }\end{array}$ \\
\hline $\begin{array}{l}\text { ECS } \\
\text { ECU } \\
\text { ETEC }\end{array}$ & $\begin{array}{l}\text { Environmental Control System } \\
\text { Electronic Control Unit } \\
\text { Expendable Turbine Engine Concept }\end{array}$ \\
\hline $\begin{array}{l}\mathrm{F} \\
\mathrm{FE} \\
\mathrm{ft}\end{array}$ & $\begin{array}{l}\text { Fahrenheit } \\
\text { Finite Element } \\
\text { Foot }\end{array}$ \\
\hline GN-10 & AlliedSignal Ceramic Components Silicon Nitride \\
\hline $\begin{array}{l}\mathrm{HIP} \\
\mathrm{hr} \\
\mathrm{HS} 25 \\
\mathrm{~Hz}\end{array}$ & $\begin{array}{l}\text { Hot Isostatic Pressing } \\
\text { Hour } \\
\text { Haynes Alloy } \\
\text { Hertz }\end{array}$ \\
\hline $\begin{array}{l}\text { ID } \\
\text { in } \\
\text { ITL }\end{array}$ & $\begin{array}{l}\text { Inner Diameter } \\
\text { Inch } \\
\text { Inner Transition Liner }\end{array}$ \\
\hline $\begin{array}{l}\mathrm{kg} \\
\mathrm{kPa} \\
\mathrm{ksi}\end{array}$ & $\begin{array}{l}\text { Kilogram } \\
\text { KiloPascal } \\
\text { Thousands of Pounds Per Square Inch }\end{array}$ \\
\hline $\begin{array}{l}\mathrm{lb} \\
\mathrm{lbm} \\
\mathrm{LCF}\end{array}$ & $\begin{array}{l}\text { Pounds } \\
\text { Pounds Mass } \\
\text { Low Cycle Fatigue }\end{array}$ \\
\hline $\begin{array}{l}\text { MA } \\
\text { MES } \\
\mathrm{Mg} \\
\mathrm{MI} \\
\mathrm{min} \\
\mathrm{mm} \\
\mathrm{MPa}\end{array}$ & $\begin{array}{l}\text { Massachusetts } \\
\text { Main Engine Start } \\
\text { Magnesium } \\
\text { Michigan } \\
\text { Minute } \\
\text { Millimeter } \\
\text { MegaPascal }\end{array}$ \\
\hline
\end{tabular}




\section{ACRONYMS AND ABBREVIATIONS (Contd)}

$\begin{array}{ll}\text { NAC } & \text { Norton Advanced Ceramics } \\ \text { NASA } & \text { National Aeronautics and Space Administration } \\ \text { NDE } & \text { Nondestructive Evaluation } \\ \text { No. } & \text { Number } \\ \text { NT154 } & \text { Norton Advanced Ceramics HIPped Silicon Nitride } \\ \text { OD } & \text { Outer Diameter } \\ \text { OH } & \text { Ohio } \\ \text { POD } & \text { Probability Of Detection } \\ \text { ppm } & \text { Parts Per Million } \\ \text { PSC } & \text { Pressure Slip Casting } \\ \text { psia } & \text { Pounds Per Square Inch Absolute } \\ \text { psig } & \text { Pounds Per Square Inch Gage } \\ \text { Pstatic } & \text { Static Pressure } \\ \text { Ptinlet } & \text { Inlet Total Pressure } \\ & \text { Revolution } \\ \text { rev } & \text { Revolutions Per Minute } \\ \text { Ipm } & \text { Ready To Load } \\ \text { RTL } & \text { Society of Automotive Engineers } \\ \text { SAE } & \text { Second } \\ \text { sec } & \text { Silicon Nitride } \\ \text { Si3N4 } & \text { Statement Of Work } \\ \text { SOW } & \\ \text { TIT } & \text { Turbine Inlet Temperature } \\ \text { Tmax } & \text { Maximum Temperature } \\ \text { TQL } & \text { Total Quality Leadership } \\ \text { U.S. } & \text { United States } \\ \text { USAF } & \text { United States Air Force } \\ 3-D & \text { Three Dimensional } \\ \text { omax } & \text { Sigma Max, Maximum Stress } \\ & \end{array}$




\subsection{SUMMARY}

This report summarizes work performed by AlliedSignal Engines, a unit of AlliedSignal Aerospace Company, during calendar year 1993, toward development and demonstration of structural ceramic technology for automotive gas turbine engines. This work was performed for the U.S. Department of Energy (DOE) under National Aeronautics and Space Administration (NASA) Contract DEN3-335, Advanced Turbine Technology Applications Project (ATTAP).

During 1993, the test bed used to demonstrate ceramic technology was changed from the AlliedSignal Engines/Garrett Model AGT101 regenerated gas turbine engine to the Model 331-200[CT] engine. The 331-200[CT] ceramic demonstrator is a fully-developed test platform based on the existing production AlliedSignal 331-200[ER] gas turbine auxiliary power unit (APU), and is well suited to evaluating ceramic turbine blades and nozzles. In addition, commonality of the 331-200[CT] engine with existing gas turbine APUs in commercial service provides the potential for field testing of ceramic components.

The 1993 ATTAP activities emphasized design modifications of the 331-200 engine test bed to accommodate ceramic first-stage turbine nozzles and blades, fabrication of the ceramic components, ceramic component proof and rig tests, operational tests of the test bed equipped with the ceramic components, and refinement of critical ceramic design technologies.

\subsection{Design}

The ceramic turbine nozzle and turbine blade designs were completed during the previous calendar year. The 1993 design activities focused on modification of the internal test bed engine structures to accommodate the ceramic components. The initial hardware drawings were completed in support of the planned engine testing, and modifications were performed, based on the engine test results.

\subsection{Eabrication}

Fabrication activities included procurement of a production Model 331-200[ER] gas turbine engine, and the necessary hardware for modifications to accommodate the ceramic turbine nozzles and blades.

An order was placed with AlliedSignal Ceramic Components (CC), in Torrance, CA, for a total of 100 ceramic turbine nozzles; 25 nozzles were received during 1993, and the remainder of the order was 
planned for delivery in 1994. An additional 100 ceramic nozzles were ordered from Norton Advanced Ceramics (NAC) in Northboro, MA.

An order was placed with NAC for a total of 100 ceramic turbine blades, and 61 blades were delivered during 1993; the remaining 39 parts on this order, with an additional order for 30 parts, is planned for delivery in 1994.

\subsection{Component Testing}

Component testing activities during 1993 included vibration testing of the ceramic turbine blades and proof testing of the ceramic blades and ceramic nozzles.

The ceramic turbine blade design was evaluated in acoustic ring tests, to characterize the unrestrained resonance mode(s). Airjet impingement spin testing was used to identify resonances with the ceramic blades installed in the metallic turbine disk.

Overspeed spin testing was used to proof test the ceramic turbine blades. Each blade was individually spin tested, inducing stress levels 56 percent higher than the maximum predicted stresses in the blade neck. All the ceramic blades were proof tested prior to the engine tests.

A ceramic nozzle proof test rig was designed and fabricated. The test rig induces transient thermal stresses in each nozzle, exceeding the predicted stress expected during an engine start by at least 25 percent. All 25 ceramic nozzles received in 1993 successfully passed this proof test.

\subsection{Ceramic Technologies}

Refinement of critical ceramic design technologies continued during 1993. Significant progress was made in the development of a ceramic hot corrosion environmental life model for silicon nitride. In addition, work was performed on the characterization of internal flaws in silicon nitride components, and on improved modeling of the pulverization of carbon particles during impact. 


\subsection{Engine Testing}

Two series of engine operational tests were performed, employing test bed engine builds with ceramic turbine blades and ceramic turbine nozzles, respectively. Over 118 hours of engine operation were successfully completed in tests of the engine equipped with ceramic nozzles, including a 100 -hour/300cycle accelerated duty cycle endurance test.

Failures occurred during both of the two planned engine tests with ceramic turbine blades, resulting in damage to the ceramic blades. In the first test, failure occurred during the initial engine start. There is strong evidence that the failure was the result of poor contact in the ceramic blade/turbine disk attachment. Corrective actions were implemented for this condition prior to further testing.

In the second engine test with ceramic blades, failure occurred after three successful starts and over 1.7 hours of operation. The most likely cause of the failure was determined to be from excessive turbine blade vibration. A plan for definitive testing to characterize the nature of the failure has been established, and testing will be performed when additional ceramic blades are available. 


\subsection{INTRODUCTION}

This report summarizes progress made in the ATTAP/331-200 Ceramic Turbine Engine Demonstration Project during 1993 by AlliedSignal Engines, Phoenix, AZ (formerly Garrett Auxiliary Power Division), a unit of AlliedSignal Aerospace Company. The Advanced Turbine Technology Applications Project (ATTAP) is a continuation of activities sponsored by the U.S. Department of Energy (DOE) to develop the technology for an improved automobile propulsion system under Title III of U.S. Public Law 95-238, "Automotive Propulsion Research and Development Act of 1978". ATTAP is performed under DOE/NASA Contract DEN 3-335, with the National Aeronautics and Space Administration (NASA) providing program management and administration.

The present DOE/NASA ATTAP/331-200 Ceramic Turbine Engine Demonstration Project continues development of ceramics technologies and design methods, and focuses fabrication development on a scaleup of demonstrated technologies to pilot-production levels. The project utilizes a reliable test bed engine based on the existing production AlliedSignal/Garrett Model 331-200 auxiliary power unit (APU), shown in Figure 1, which has proven capability for long-term endurance testing.

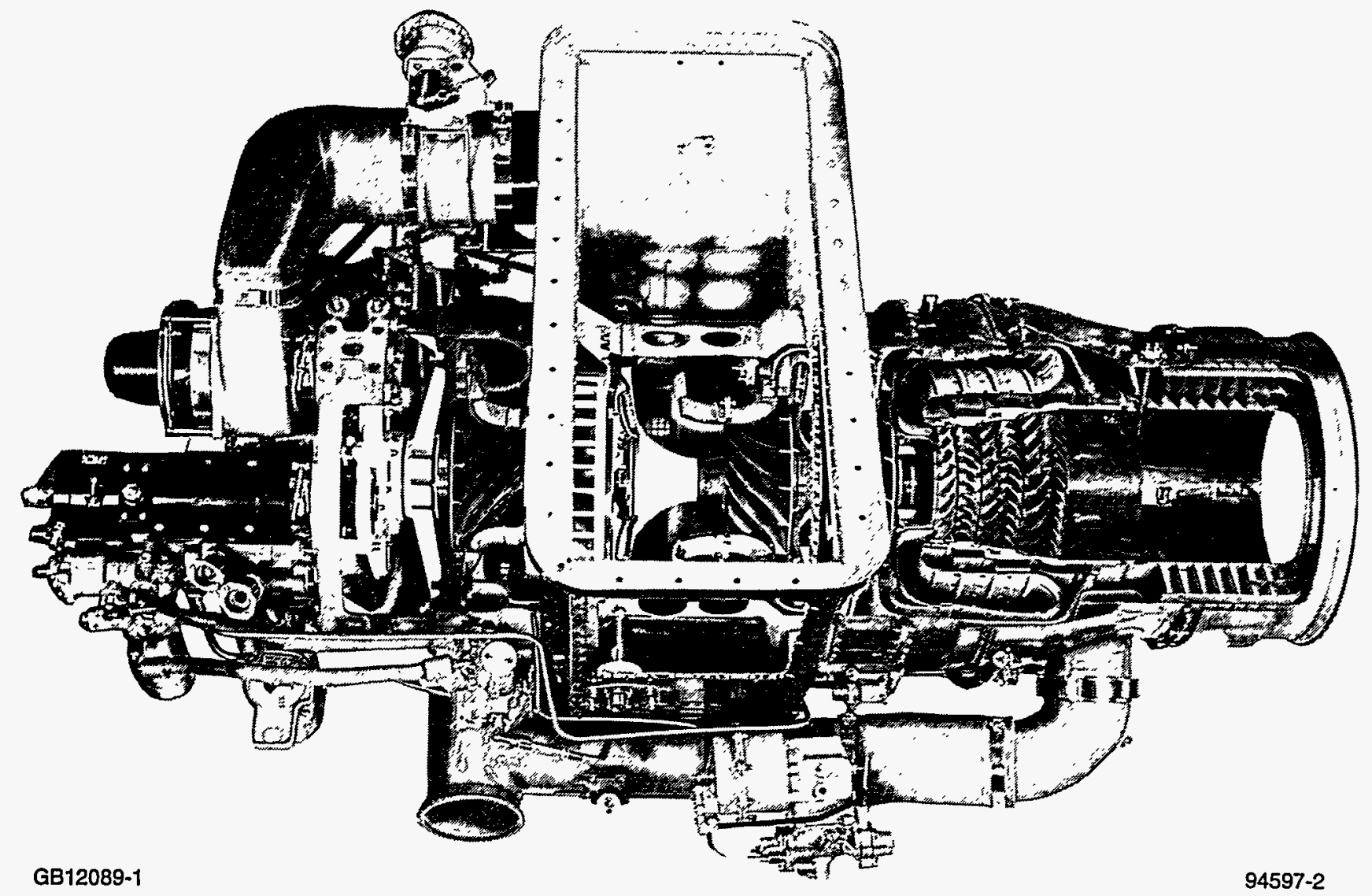

Figure 1. AlliedSignal/Garrett Model 331-200 APU Used As ATTAP Test Bed Engine Has Proven Capability For Long-Term Endurance Testing. 
The new 331-200[CT] ceramic technology test bed provides additional capability over the AGT101 test bed engine used in prior years of the Advanced Gas Turbine (AGT) and ATTAP programs. By virtue of its high reliability and potential for field testing, the 331-200[CT] will enable the accumulation of very high operating times, while exposing the ceramic components to many of the random failure modes that actually exist in production engine applications. In addition, designing ceramic components and demonstrating them in this engine focuses on the mechanical aspects of integrating ceramics into gas turbines, which is a principal barrier to commercialization of ceramic turbine technology.

The relatively low operating temperature of $1800 \mathrm{~F}$ (988C) in the $331-200[\mathrm{CT}]$ test bed presents only a minor tradeoff in effectiveness for evaluation of ceramic turbine components. Although this condition does not challenge the temperature capability of the ceramic materials, other critical ceramic design aspects such as contact, impact, vibration, and various fast fracture failure modes are challenged in this test bed and its fielded applications. In the future, commercial applications of the ceramic technologies proven in this test bed will be able to successfully take maximum advantage of the higher temperature capability of the ceramic materials, but only after the mechanical design issues are fully understood and resolved.

The thrust of the ATTAP/331-200 program is to "bridge the gap" between structural ceramics in the laboratory and near-term commercial heat engine applications. The intent is to use this application as a stepping stone to transition ceramics technology into the automotive marketplace, where the benefits will have the greatest impact on reducing fuel consumption and gaseous emissions. The current ATTAP project goal is to support the accelerated commercialization of advanced, high-temperature engines for hybrid vehicles and other applications. The objectives of this project are to provide essential and substantial early field experience demonstrating the reliability and durability of ceramic components in modified, available, gas turbine engine application; and to scale-up and improve the manufacturing processes of ceramic turbine engine components and demonstrate application of these processes in the production environment. Simultaneously, this work will ready ceramics technology for the aircraft APU application, while gathering extensive laboratory and field experience, and further develop and improve ceramic component design methods and fabrication techniques. In this way, the ATTAP/331-200 program will effectively support expansion of ceramics technology into automotive engine designs.

The overall ATTAP/331-200 program plan provides an approach to resolve each of these issues. The discussions in the following sections of this report describe the progress to date in the various ATTAP activities and outline the go-forward plans to meet the program objectives. 


\subsection{TURBINE STAGE DESIGN, PRELIMINARY MODELING, AND ANALYSIS}

The existing production, all-metallic AlliedSignal Model 331-200[ER] APU first-stage turbine assembly was redesigned to incorporate ceramic nozzle segments and inserted ceramic turbine blades. Design guidelines for the 331-200[CT] configuration recognized that the redesigned components will be used in a later field evaluation program, in which engines equipped with the ceramic components will replace production all-metallic engines; thus, the ceramic-equipped engines must be aerodynamically similar to the all-metallic engines. In addition, to maintain the reliability of the test bed, modifications to the metallic engine supporting structures were minimized.

The ceramic turbine nozzle segments and blades were designed with principal consideration given to component producibility, while also satisfying structural integrity and aerodynamic performance requirements.

\subsection{Blade And Disk Design}

The goal of the ceramic blade, metallic disk, and blade retention component detail design was to maintain the simplicity of a production design while incorporating the latest developments in ceramic design and techniques. The ceramic turbine design was constrained by the current production 331200[ER] engine flowpath, physical speed, turbine inlet temperatures, airflow, and turbine efficiency requirements.

In addition to material requirements, the ceramic turbine stage component designs gave special consideration to the following:

- Fabrication processes for the ceramic components

- Geometric requirements for fabrication

- Vibration environment in which the parts will perform

- Attachment of the ceramic parts to the metallic structures

- Minimum susceptibility for impact damage.

The design cycle conditions for the 331-200[CT] ceramic turbine stage are listed in Table 1. 
TABLE 1. 331-200[CT] CERAMIC TURBINE DESIGN CYCLE CONDITIONS

\begin{tabular}{|l|l|l|}
\hline \multicolumn{1}{|c|}{ Parameter } & \multicolumn{1}{c|}{ Units } & \multicolumn{1}{c|}{ Value } \\
\hline \hline Corrected Flow & $\mathrm{lbm} / \mathrm{sec}(\mathrm{kg} / \mathrm{sec})$ & $1.556(0.7058)$ \\
\hline Corrected Speed & $\mathrm{rpm}$ & 19,993 \\
\hline Physical Speed & $\mathrm{rpm}$ & 41,731 \\
\hline Pressure Ratio & -- & 8.741 \\
\hline Efficiency & percent & 85.7 \\
\hline Inlet Total Temperature & $\mathrm{F} \mathrm{(C)}$ & $1800(982)$ \\
\hline Inlet Total Pressure & psia (kPa) & $129.8(895)$ \\
\hline
\end{tabular}

The 331-200[CT] ceramic turbine blade and disk system is shown in Figure 2. A design review was held in April 1993, to confirm the design and analysis with the NASA program managers. The detailed analysis of the turbine blade consisted of four key aspects: aerodynamic performance, vibration, stress analysis, and component life prediction. The review is summarized in the following subsections.

\subsubsection{Nozzle And Blade Aerodynamic Design}

The existing production 331-200[ER] APU employs a three-stage axial turbine design. Only the first axial turbine stage was redesigned with ceramic components; the second and third stages were left unchanged. The existing engine envelope, size, and axial length constraints permitted only minor changes to the turbine gas flowpath. Aerodynamic similarity of the ceramic first-stage turbine design was maintained with the original (all-metallic) design, allowing the ceramic nozzle assembly and ceramic turbine rotor assembly to be substituted for the all-metallic assemblies without affecting the aerodynamic performance.

Mechanical integrity and manufacturability were made the highest priorities for the ceramic blade and nozzle segment designs. Where necessary, these aspects of the ceramic component configurations were maximized, at the possible expense of optimum aerodynamic design. If future testing with the ceramic components indicates that the resulting aerodynamic performance is unacceptable, then the aerodynamic designs may be adjusted. 


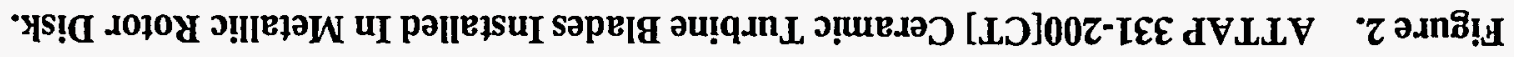

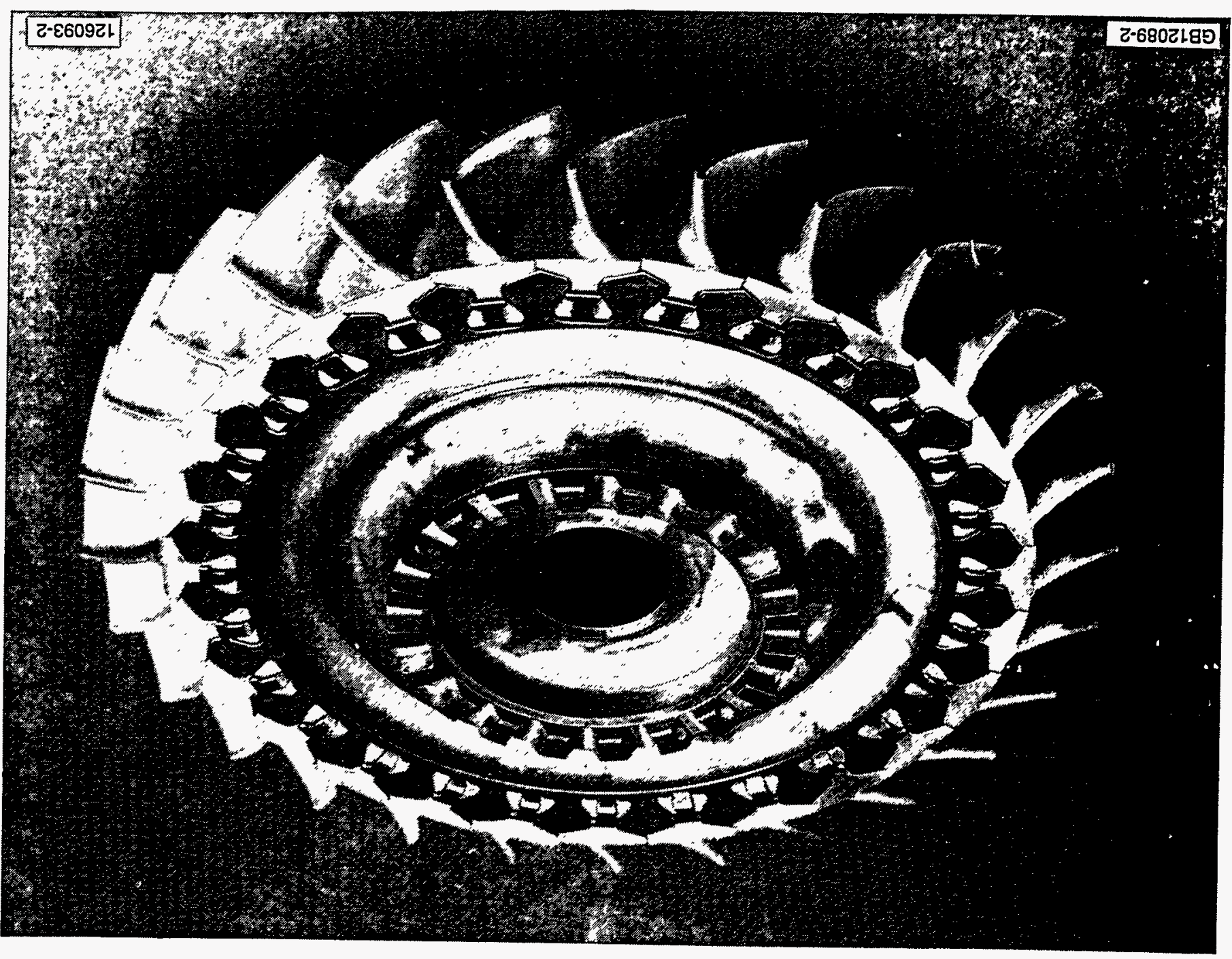


Significant aerodynamic design changes were made in the nozzle and blade vane counts. The blade count was reduced from 36 to 28 , in order to make additional space in the disk for the single lobe, dovetail blade attachment design. The decreased blade count increases the aerodynamic loading on the blade to the maximum allowable level. The blade geometry was manipulated to maximize airfoil stiffness, to keep the first resonant frequency above the blade passing frequencies from the first- and second-stage nozzles.

In addition, the blade leading edge tip thickness was limited to a minimum of 0.080 inch $(2.0 \mathrm{~mm})$, for improved resistance to potential particle impact damage. This design value was based on experience learned in the Defense Advanced Research Projects Agency (DARPA)/U.S. Navy Ceramic Gas Turbine Engine Demonstration Program. ${ }^{(1)}$

The aerodynamic design of the ceramic nozzle was influenced by mechanical and manufacturing considerations. Mechanical integrity and manufacturing considerations drove the nozzle design toward a thicker trailing edge and more constant cross section thickness. The number of vanes in the nozzle assembly was influenced by the desire to minimize the parts count and also avoid vibration interactions with the ceramic blades.

The resulting ceramic nozzle design employs a vane with a relatively thick trailing edge of 0.035 inch $(0.9 \mathrm{~mm})$ nominal thickness, and a vane count reduced to 23 segments. This compares with the allmetallic nozzle vane trailing edge thickness of 0.030 inch $(0.8 \mathrm{~mm})$ and a vane count of 29 segments. The new ceramic design was determined to be acceptable in aerodynamic blockage, mechanical stress, and manufacturability. However, as a result of the reduced counts for the turbine blades and nozzle vanes, both components are highly loaded aerodynamically.

Three dimensional (3-D) inviscid flow analyses were performed on both ceramic components using the DENTON and DAWES computer codes. The nozzle loading values, shown in Figure 3 , show that despite localized step-like variations in the leading edge suction and trailing edge pressure surfaces, both pressure and suction side surfaces should have acceptable diffusion.

(1) DARPA/U.S. Navy Turbine Demonstration Program, Contract No. N00024-76-C-5352, 1976 through 1981. 


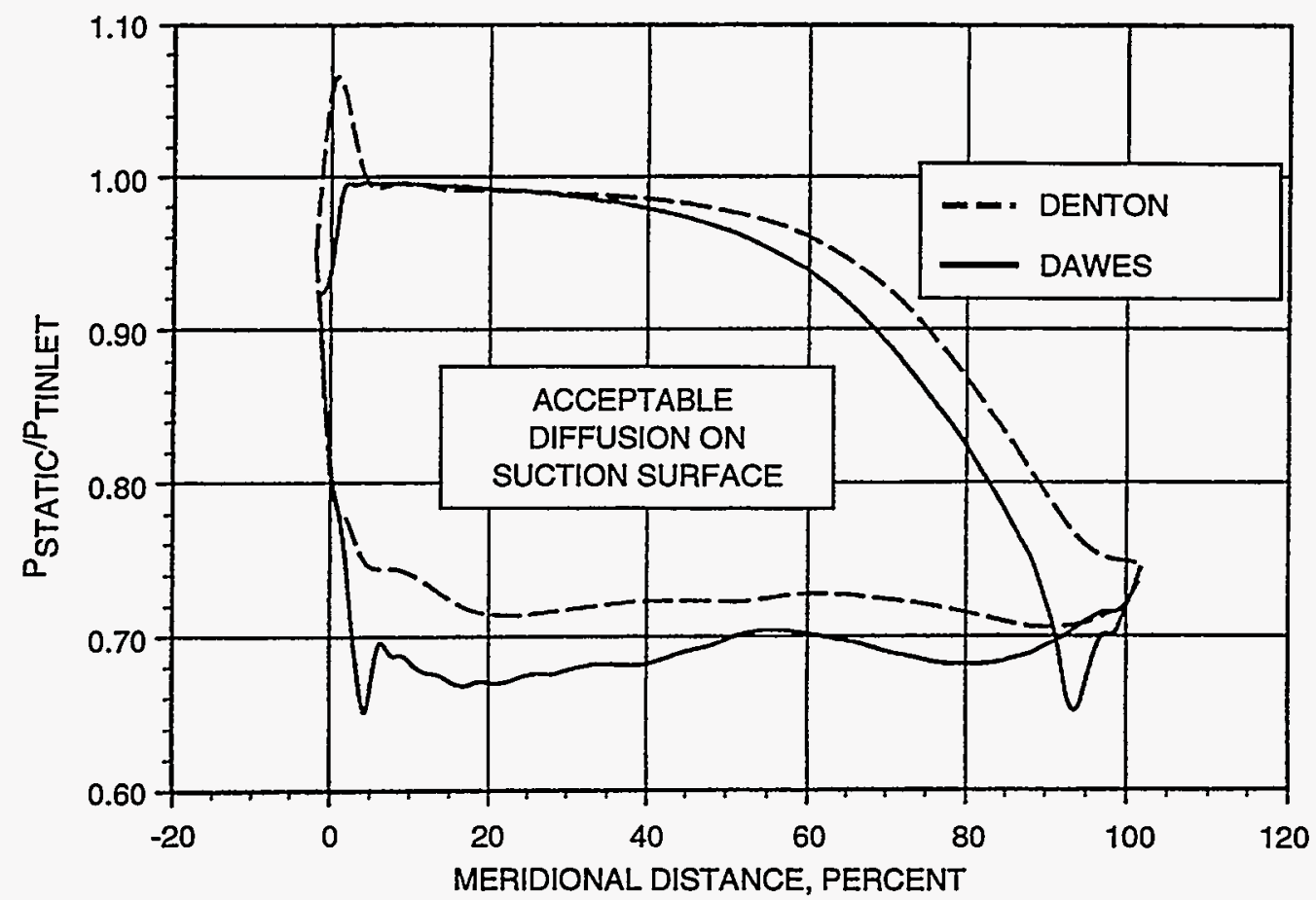

GC12089-3

Figure 3. Three-Dimensional Inviscid Flow Analysis Results Show Acceptable Diffusion For ATTAP/331-200[CT] Ceramic Nozzle Design.

The analysis results for the ceramic blade indicate that the diffusion is acceptable at the hub and the midspan [Figure 4(a), top], but the loadings calculated for the blade tip [Figure 4(b), bottom] indicate unacceptable diffusion. However, the physical effect of blade tip clearance and the subsequent leakage created typically degrade performance in this area of a turbine blade. Optimizing the blade tip clearance will be particularly important in realizing the performance potential of the ceramic blades.

\subsubsection{Blade Vibration Analysis}

The stringent blade vibration frequency goals for the 331-200[CT] design made necessary multiple aero/mechanical design iterations to achieve the current ceramic airfoil geometry. The initial objective was to minimize the number of blade resonant frequencies within the operating range of the ceramic blade equipped engine.

The Campbell diagram in Figure 5 shows the vibration analysis results for the final airfoil configuration with a rigid attachment. The frequency margin achieved was more than 10 percent between the first mode frequency of the blade and the passing frequencies of the upstream and downstream nozzles. All higher mode frequencies were anticipated to be free of potential excitation due to the gaspath components. 


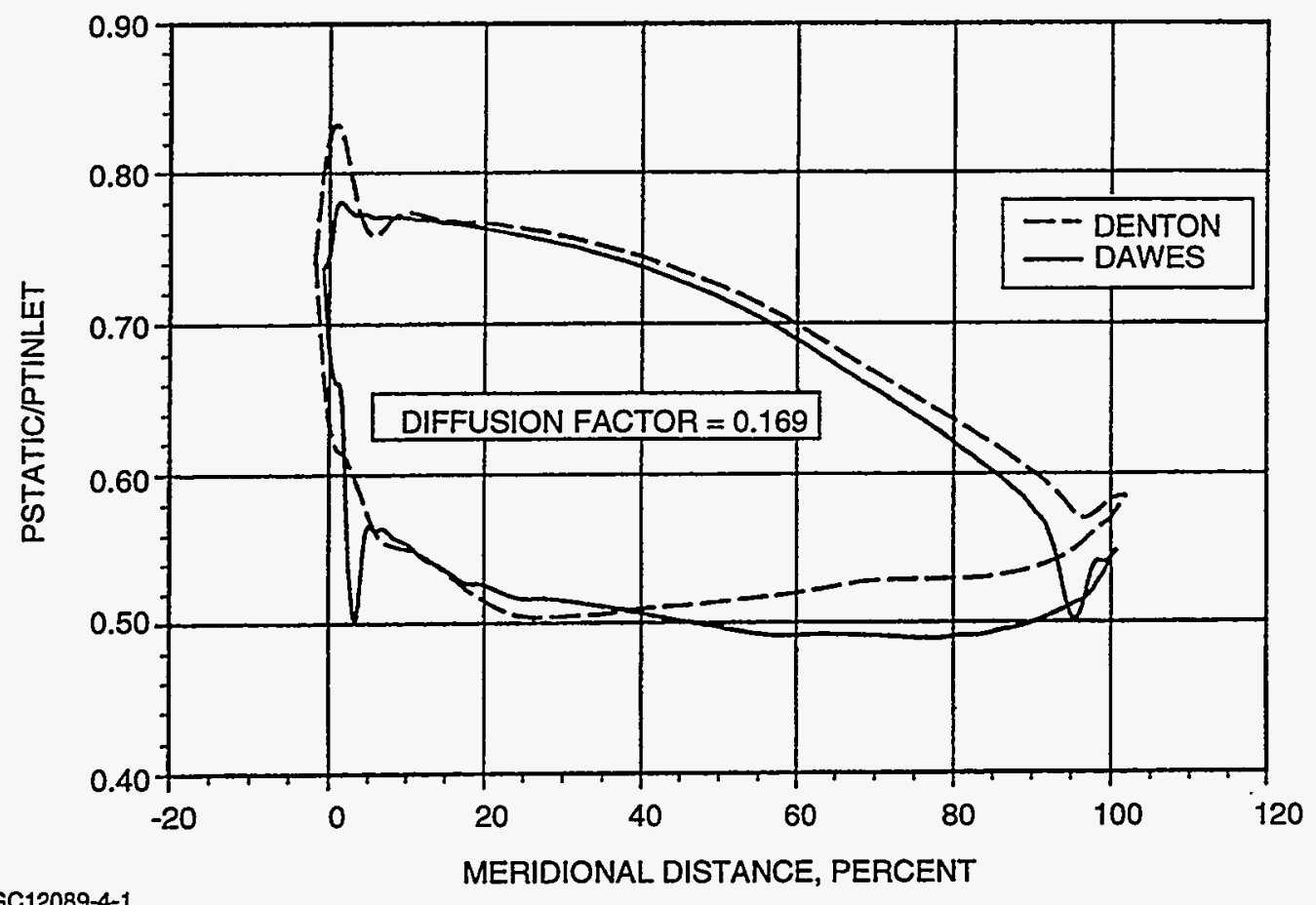

(a) Hub And Mid Span

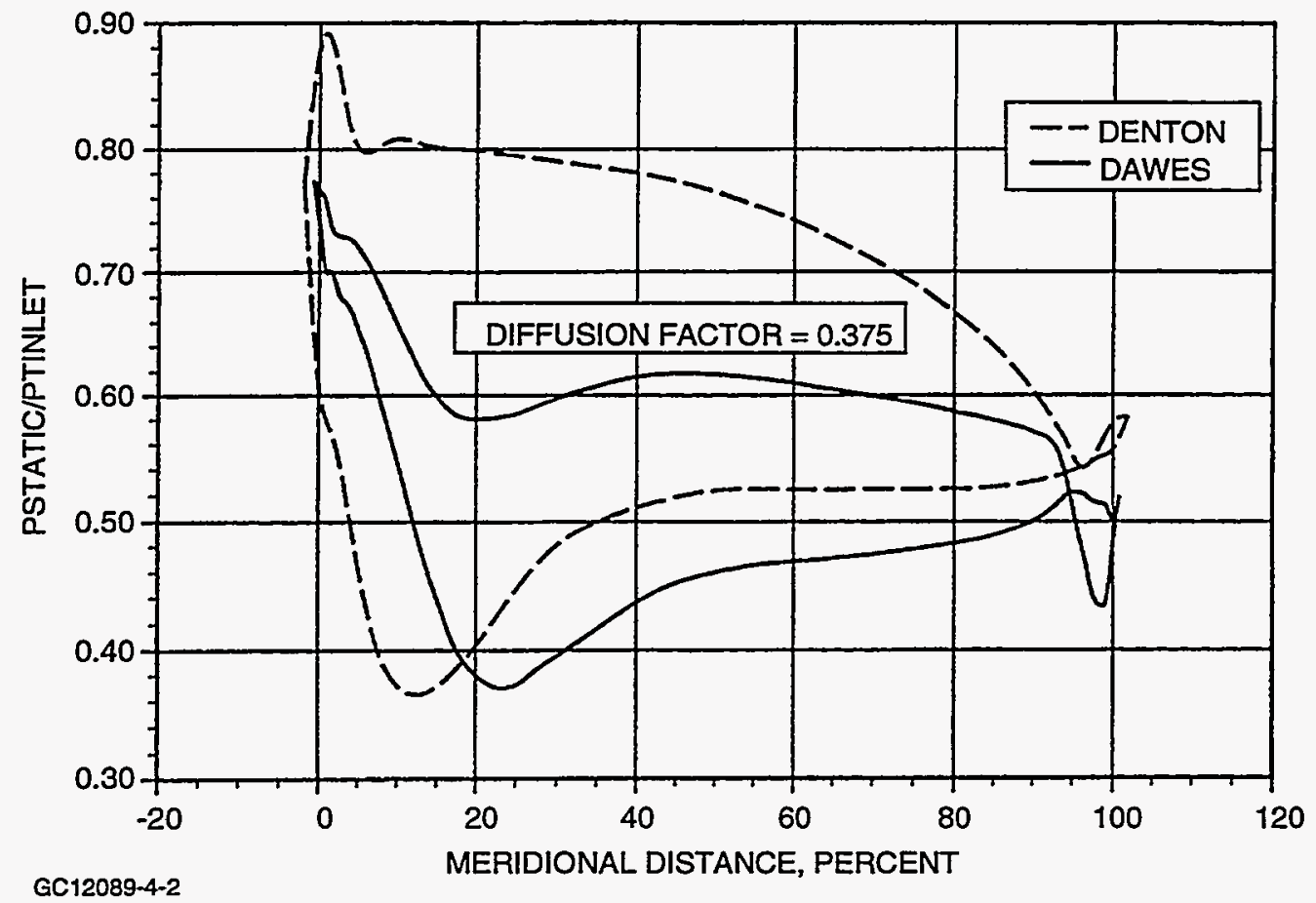

(b) Blade Tip

Figure 4. Inviscid Flow Analysis Results For ATTAP/331-200[CT] Ceramic Turbine Blades Indicate: (a) Satisfactory Diffusion At Hub And Mid Span, And (b) Typical Degraded Performance At The Blade Tip, Which May Be Corrected By Optimizing Tip Clearance. 


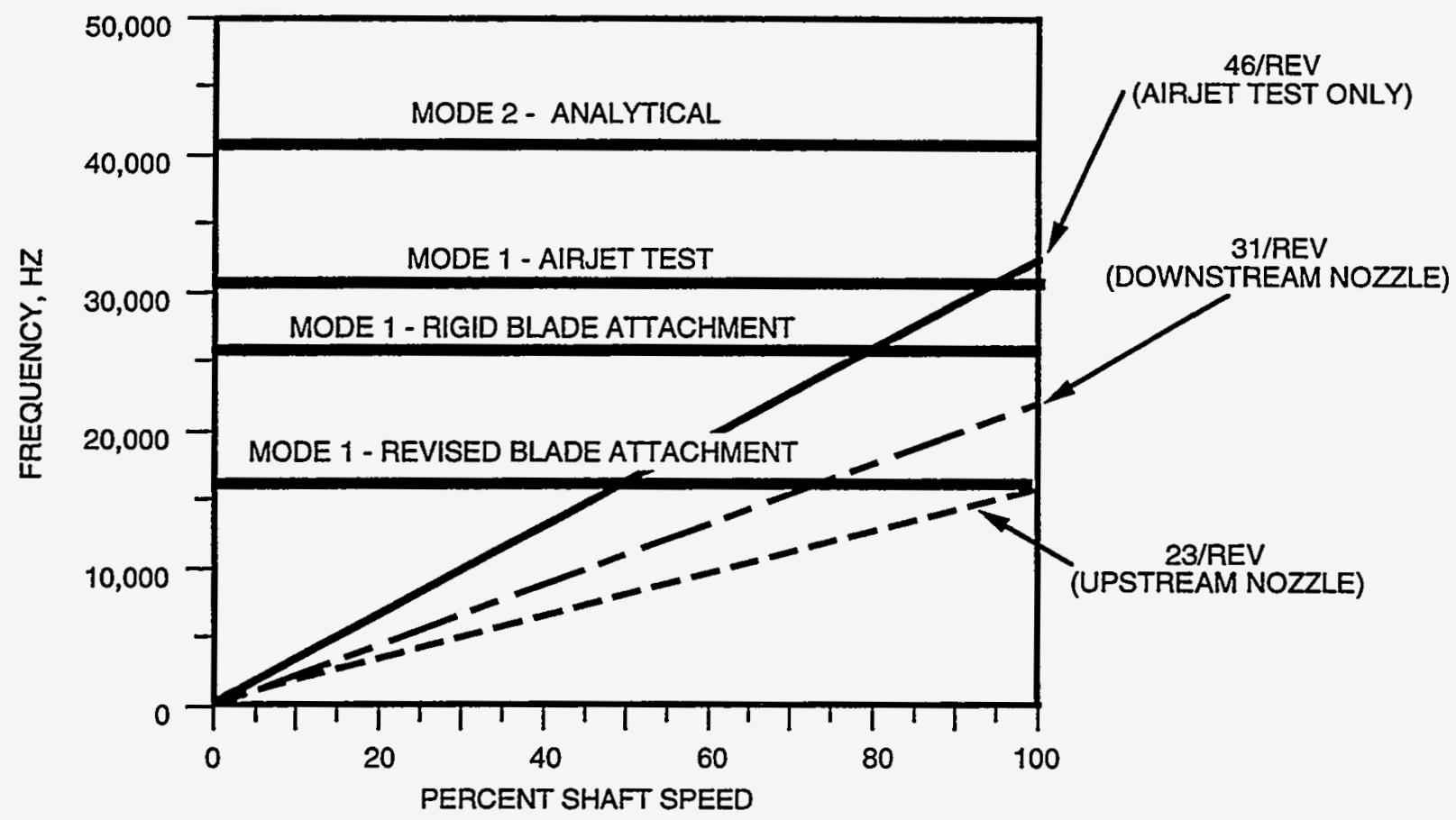

GC12089-5A

Figure 5. Campbell Diagram For Final ATTAP/331-200[CT] Ceramic Blade Airfoil Design Indicates Acceptable Vibration Frequency Margin.

Following these initial results, the judgment was made that further manipulations of the ceramic turbine blade geometry to increase the margin would be ineffective and possibly counterproductive. The blade geometry closely resembled that of the ceramic blade successfully used in the earlier DARPA/Navy Program in terms of maximum thickness and taper ratio. Further changes in blade geometry were not made because there was concern that further blade thickening to increase stiffness might needlessly degrade the aerodynamic performance without achieving an effective improvement in vibration margin.

The vibration analysis was repeated after optimization of the blade attachment geometry. The revised attachment (discussed in the next section) lowered the first blade resonant mode from $26,000 \mathrm{~Hz}$ to $16,300 \mathrm{~Hz}$, which is within the range of excitation during engine operation. This reduction in resonant frequency is of particular concern when the ceramic blades are matched with the 23-count ceramic nozzle assembly. As shown in Figure 5, vibration interference is predicted to occur near the engine design speed. For this reason, the ceramic blades will be operationally evaluated with the 29-count metallic turbine nozzle assembly until the vibration issues are resolved. The second resonant mode was predicted to be $30,000 \mathrm{~Hz}$, still above the range of engine excitation. 
Bench and engine testing of ceramic blades of this design will be performed to provide a better understanding of the criticality of the blade vibration margin.

\subsubsection{Blade Stress Analysis}

Ceramic blade stress analysis results are summarized in Figure 6. The geometry of the blade attachment was optimized to produce minimum bearing stress. Predicted peak stress of $43 \mathrm{ksi}(296 \mathrm{MPa})$ occurs on the dovetail surface of the blade. This attachment geometry is shown in Figure 7. Through comparison with existing AlliedSignal Engines experience, a high probability of success in operation was indicated.

A life analysis was performed for the full rotor assembly with 28 ceramic blades. The analysis result was 99.9 percent nominal probability of success for 20,000 cycles (20,000 hours operation).

\subsubsection{Blade Axial Retention}

A bent tab system, shown in Figure 8, was selected early in the design process for axial retention of the ceramic blades, and the design details and drawings were completed during 1993.

Bent tabs are a method of axial blade retention that has been successfully used in several AlliedSignal/Garrett turbines, including the baseline production Model 331-200[ER] APU (the ATTAP test bed). Key considerations in the design of the bent tab were proper control of gas leakage through clearance areas around the bent tab, and positioning of the bent tab to avoid inducing additional contact stresses in the ceramic blade.

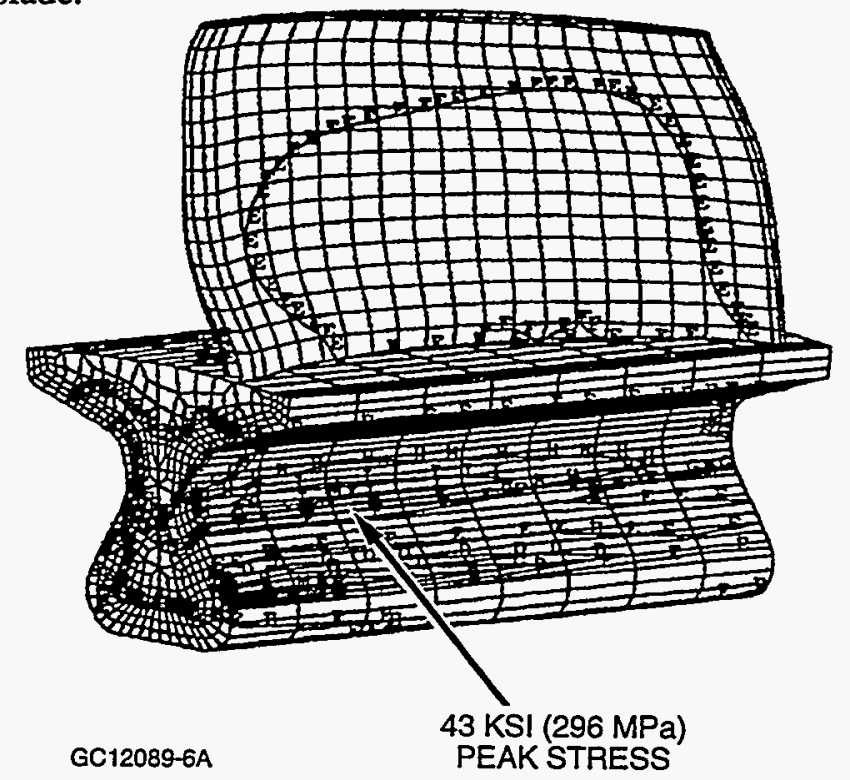

Figure 6. Ceramic Blade Stress Analysis Results Were Satisfactory. 


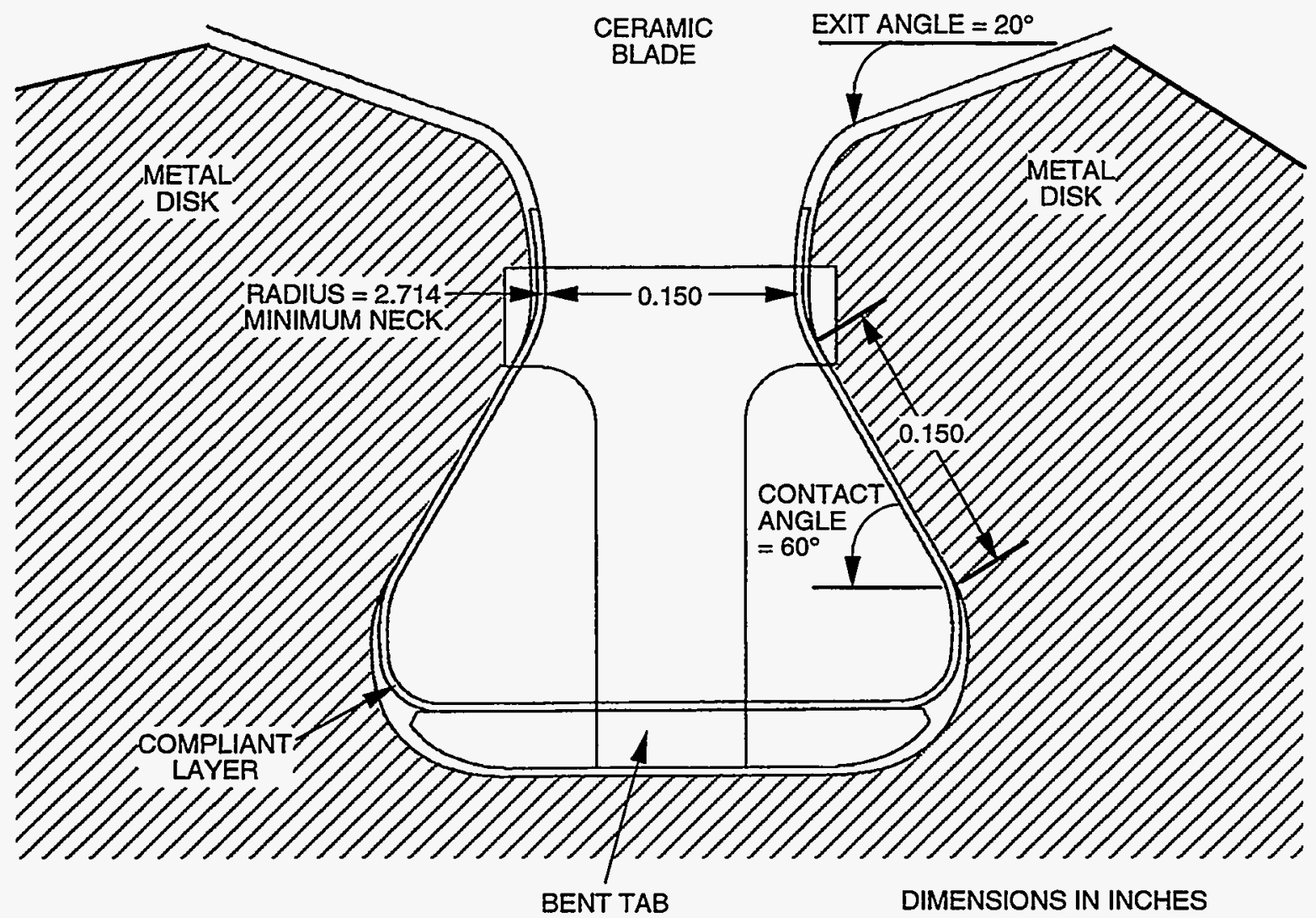

GC12089-7A

Figure 7. Ceramic Turbine Blade Attachment Geometry Was Optimized. 


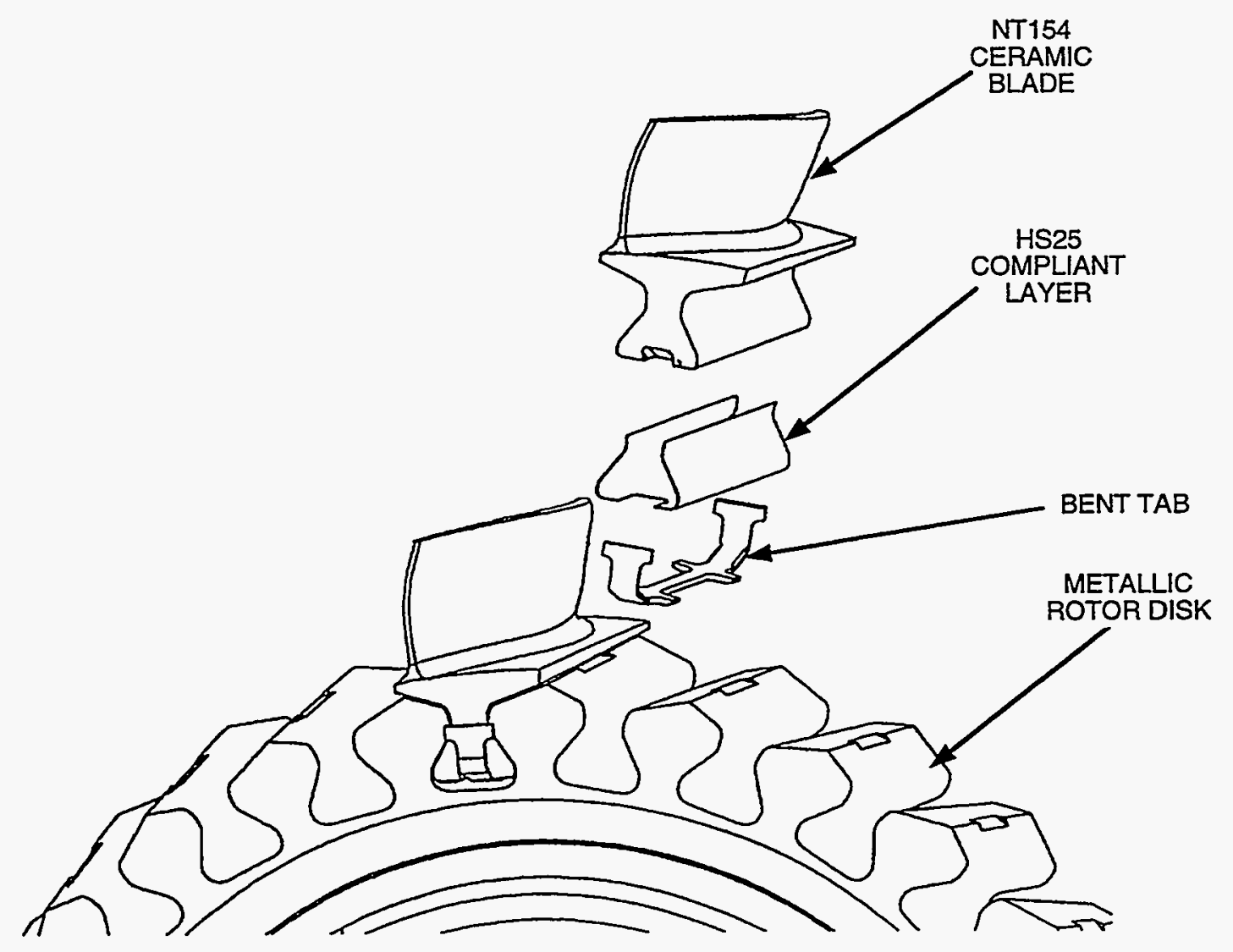

GC12089-8B

Figure 8. ATTAP 331-200[CT] Axial Ceramic Blade Retention Scheme Employs A Bent Tab And Compliant Layer.

Minimizing the gas leakage through the blade attachment slot is critical to prevention of hot gas ingestion into the turbine cavities and control of the temperatures in the turbine disk.

The positioning of the bent tab is important for two reasons: first, to ensure that the bent tab does not slide or twist in the slot, to prevent translation of the blade in the slot; second, to prevent the tab from wedging into the corner radius between the ceramic blade and the disk, to avoid high localized contact stresses during engine rolldown.

To control slot leakage, the clearance must be minimized between the ceramic blade, the compliant layer, and the rotor disk. This requires tight control of the tangential positioning of the bent tab relative to the disk attachment slot. The bent tab was also designed to block secondary cooling air leakage through the attachment slot in the disk, through the incorporation of "wings". These features help block the flow while also minimizing the mass of the bent tab. 
Notches were added to the ceramic blade attachment for tangential positioning, and the bent tab was pre-bent for placement on the blade during assembly, prior to being inserted into the disk.

\subsubsection{Blade Compliant Layer}

The purpose of the blade compliant layer is to isolate the ceramic portion of the blade attachment from the irregularities between the blade and the mating surfaces in the metallic rotor disk, which could cause ceramic failure from high localized contact stresses. Similar compliant layers have been successfully demonstrated by AlliedSignal in the earlier DARPA/U.S. Navy Turbine Demonstration Program $^{(1)}$ and the U.S. Air Force (USAF) Expendable Turbine Engine Concepts (ETEC) Program ${ }^{(2)}$ For the present ATTAP program, the compliant layer chosen is a 0.005 inch $(0.13 \mathrm{~mm})$ thickness foil of Haynes HS25 alloy (Figure 8).

\subsubsection{Disk Design}

All 331-200[CT] disk design and analysis work was completed prior to 1993. The analysis results showed disk stresses and temperatures would be well within the range of AlliedSignal experience, and the predicted disk low cycle fatigue (LCF) life is greater than 20,000 cycles.

\subsection{Nozzle Design And Analysis}

The initial ceramic nozzle design details and drawings were completed in 1992. The ceramic nozzle system is shown in Figure 9. The individual ceramic segments are captured in the metallic support with a molded ceramic post feature.

Temperature and stress analysis results for the ceramic nozzle indicate acceptable levels during engine operation. The peak stresses in the ceramic turbine nozzles are driven by the temperature differential within the part during engine starting. The highest stresses during the starting transient occur at the leading and trailing edges of the nozzle airfoils, as these thinner sections rapidly heat up. The peak stress occurs nine seconds into the start, when the temperature gradient at the nozzle midspan is also greatest, as shown in Figure 10.

(2)USAF Expendable Turbine Engine Concepts (ETEC) Program, Contract No. F33657-85-C-0253, 1985 to present. 


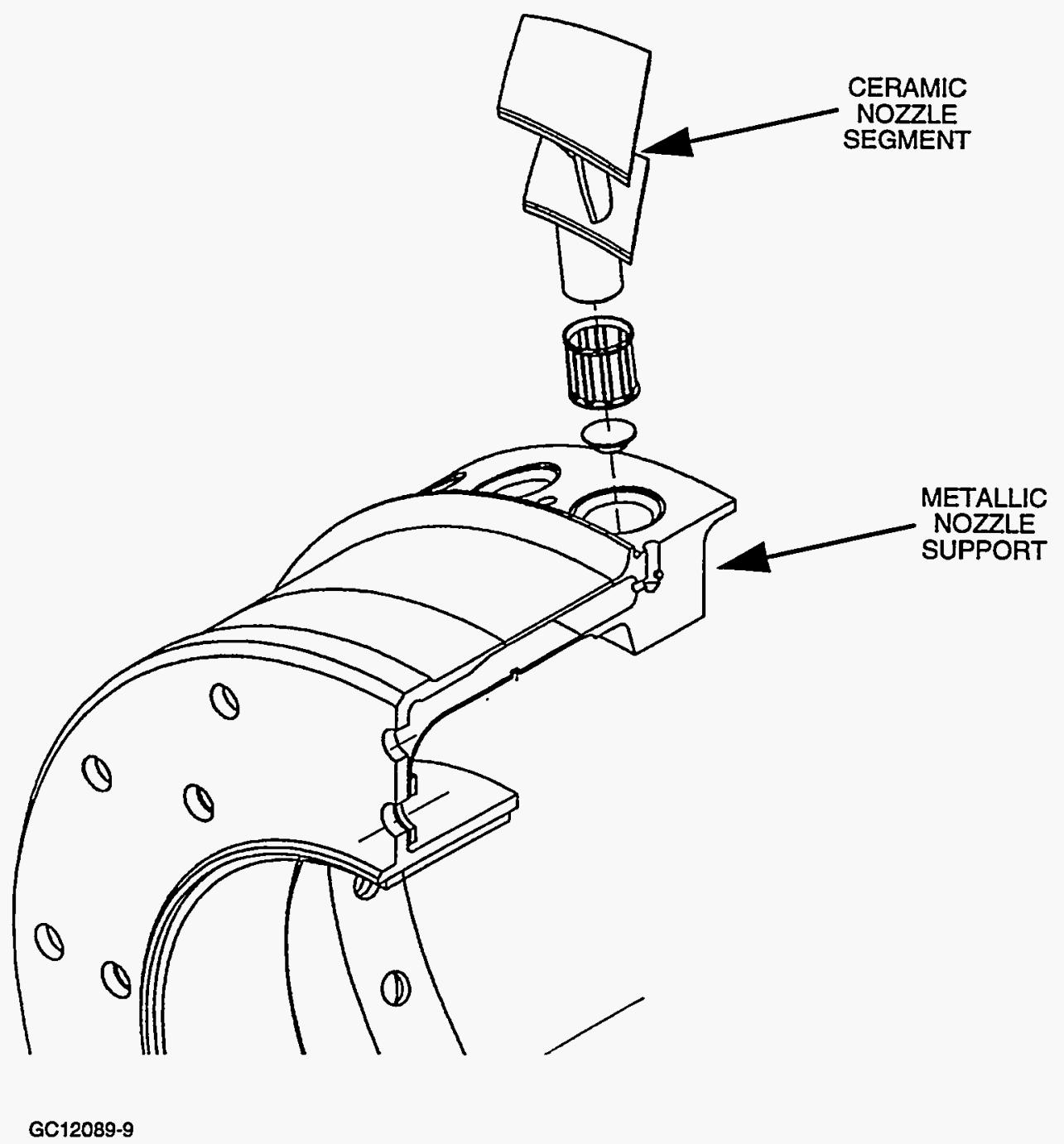

Figure 9. Baseline ATTAP 331-200[CT] Ceramic Nozzle Design Was Completed In 1992. 


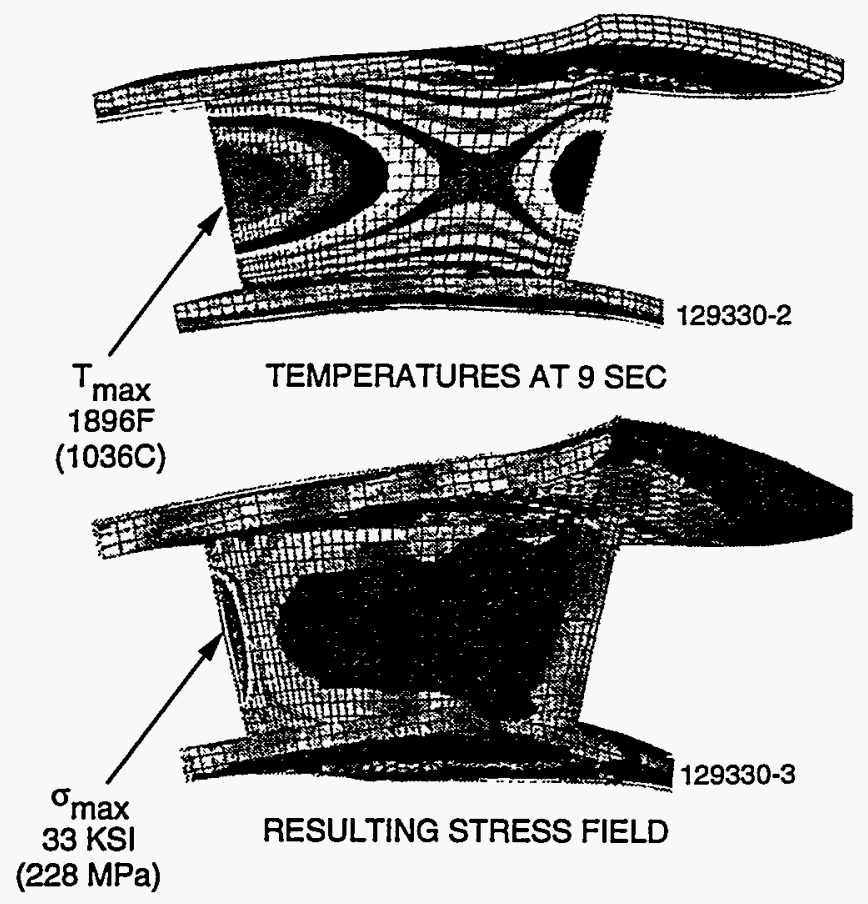

TEMPERATURE GRADIENT FROM 50 PERCENT CHORD TO 100 PERCENT CHORD (AT MIDSPAN)

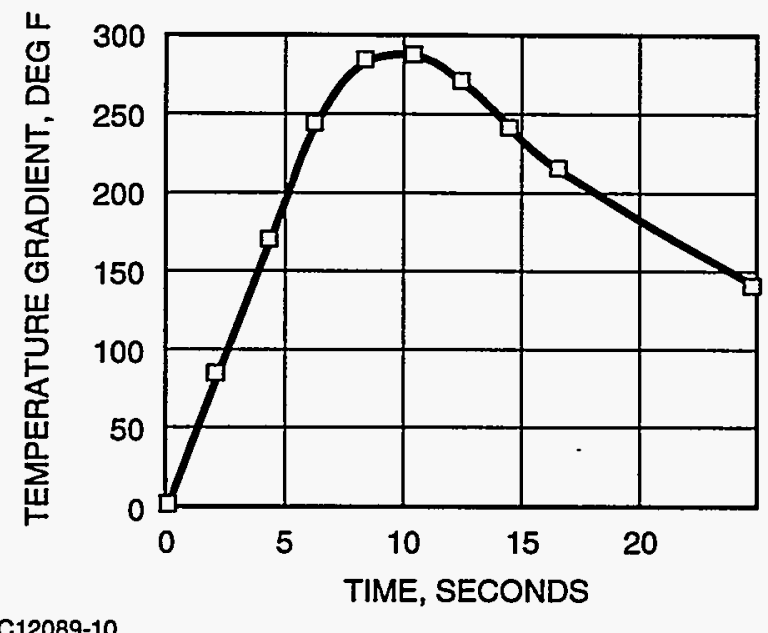

Figure 10. Predicted Peak Temperature And Stress Values For ATTAP/331-200[CT] Ceramic Nozzle Occur During Engine Startup. 
Continuing design efforts through the first half of 1993 were devoted to coordination with the ceramic nozzle vendor, and incorporation of vendor-requested design and drawing modifications for improved manufacturability. Redesign activity was initiated to modify the ceramic nozzle design features to enable net-shape forming and to enhance durability. The primary feature changes were the inclusion of draft to allow proper mold tooling removal ("pull" allowance) from the nozzle, and thickening of the vane airfoil for improved material flow during forming. These features are shown in Figure 11.

The work to include draft in the ceramic nozzle sidewalls resulted in gaspath endwall contours that were atypical of conventional metallic designs, which are typically surfaces of revolution. A significant amount of 3-D surface and solid modeling work was required to verify the tool pull characteristics, while ensuring that the correct required throat area of the ceramic nozzle was maintained.

The geometric changes to the airfoil resulted in thickening of the leading edge to provide better material flow during the molding process, and enhanced durability through increased impact strength. The ceramic nozzle design activities will continue into 1994.

\subsection{Structure Design And Analysis}

The primary structural design concepts for the ceramic turbine 331-200[CT] were established in 1992, with the design details and drawings being completed in early 1993 . Significant structural changes from the all-metallic engine configuration (highlighted in Figure 12) included:

- The ceramic nozzle support retention features and attachment to the rest of the engine structure

- An OD seal to provide radial sealing on the outer surface of the ceramic nozzles

- A Belleville washer in the outer structure system to accommodate thermal deflections without developing large interference loads.

Initial engine testing indicated higher than anticipated structural and gas temperatures in the outer structure. Hardware inspection results, and thermocouple and pressure test data indicated the potential for excessive cooling air leakage, resulting in ingestion of hot gaspath air (see Figure 13). Modifications were then made to the outer structure to enhance sealing at the interfaces, and to reduce thermal deflections (see Figure 14). Subsequent engine testing showed temperature reductions of 200 to $300 \mathrm{~F}$ (93 to $150 \mathrm{C}$ ). 

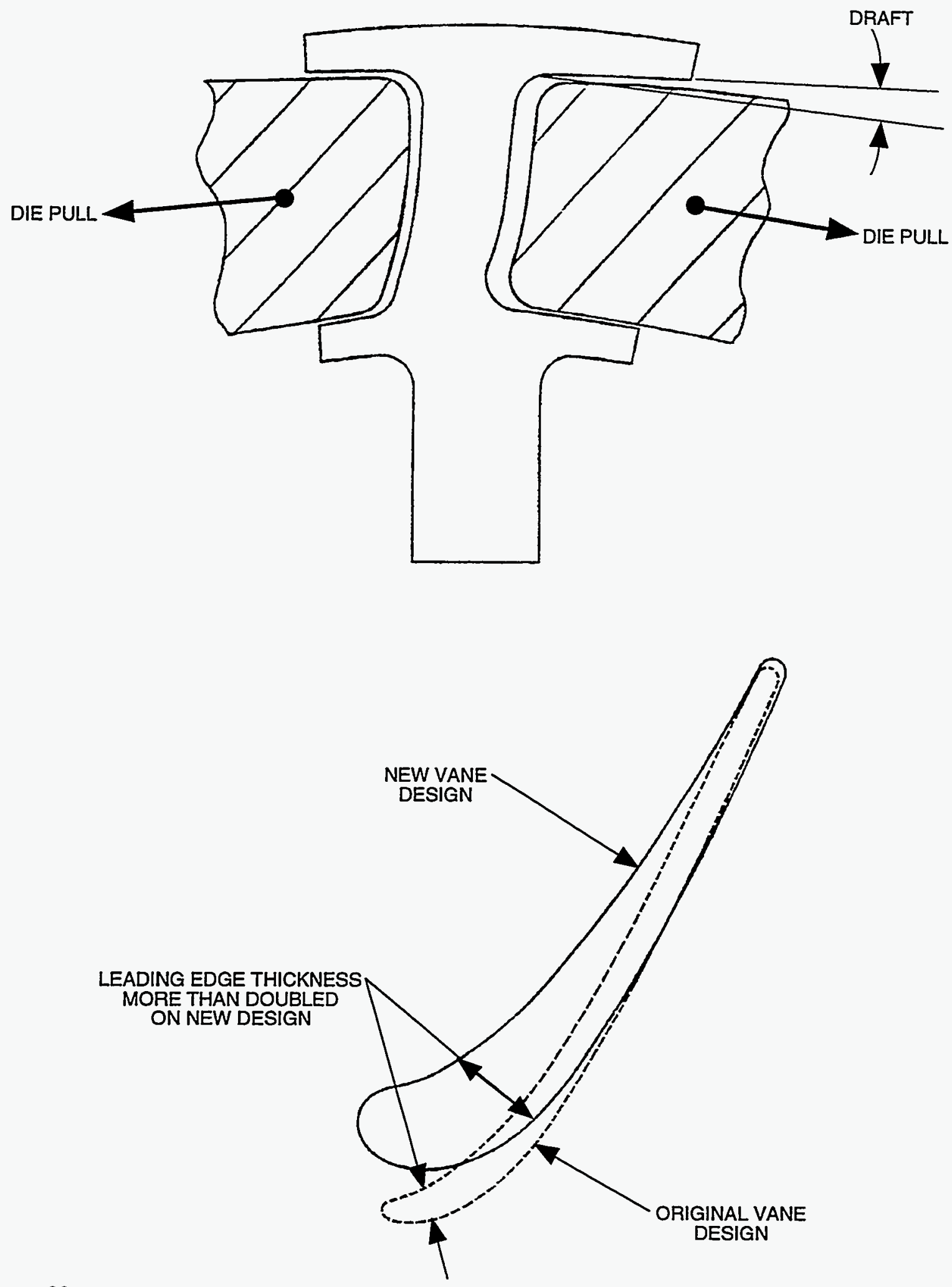

GC12089-11

Figure 11. ATTAP Ceramic Nozzle Redesign Efforts In 1993 Included Changes For Improved Manufacturability. 


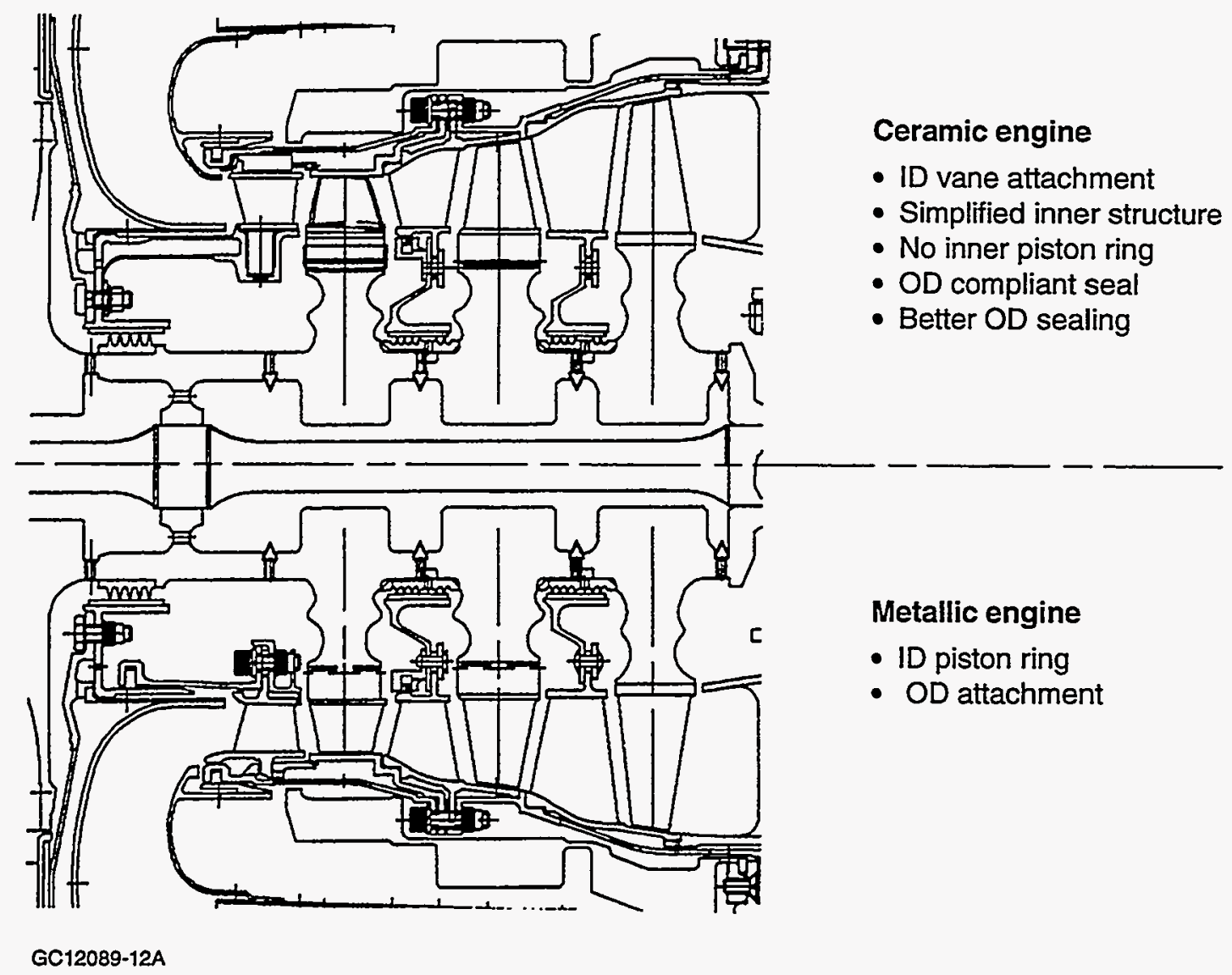

Figure 12. ATTAP/331-200[CT] Structural Design Incorporates Features To Accommodate Ceramic Turbine Components.

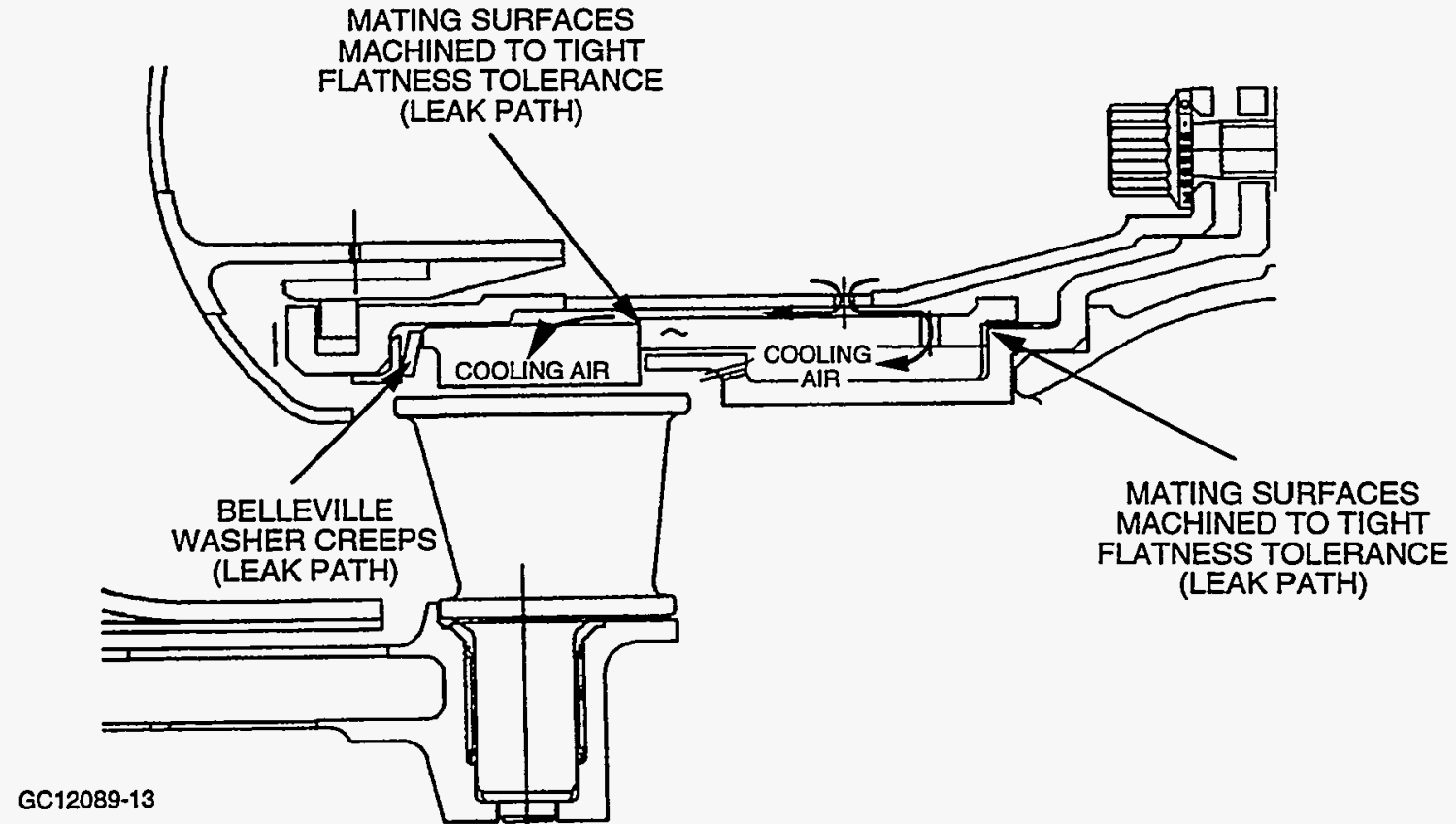

Figure 13. Initial Engine Test Results Indicated Excessive Cooling Air Leakage. 


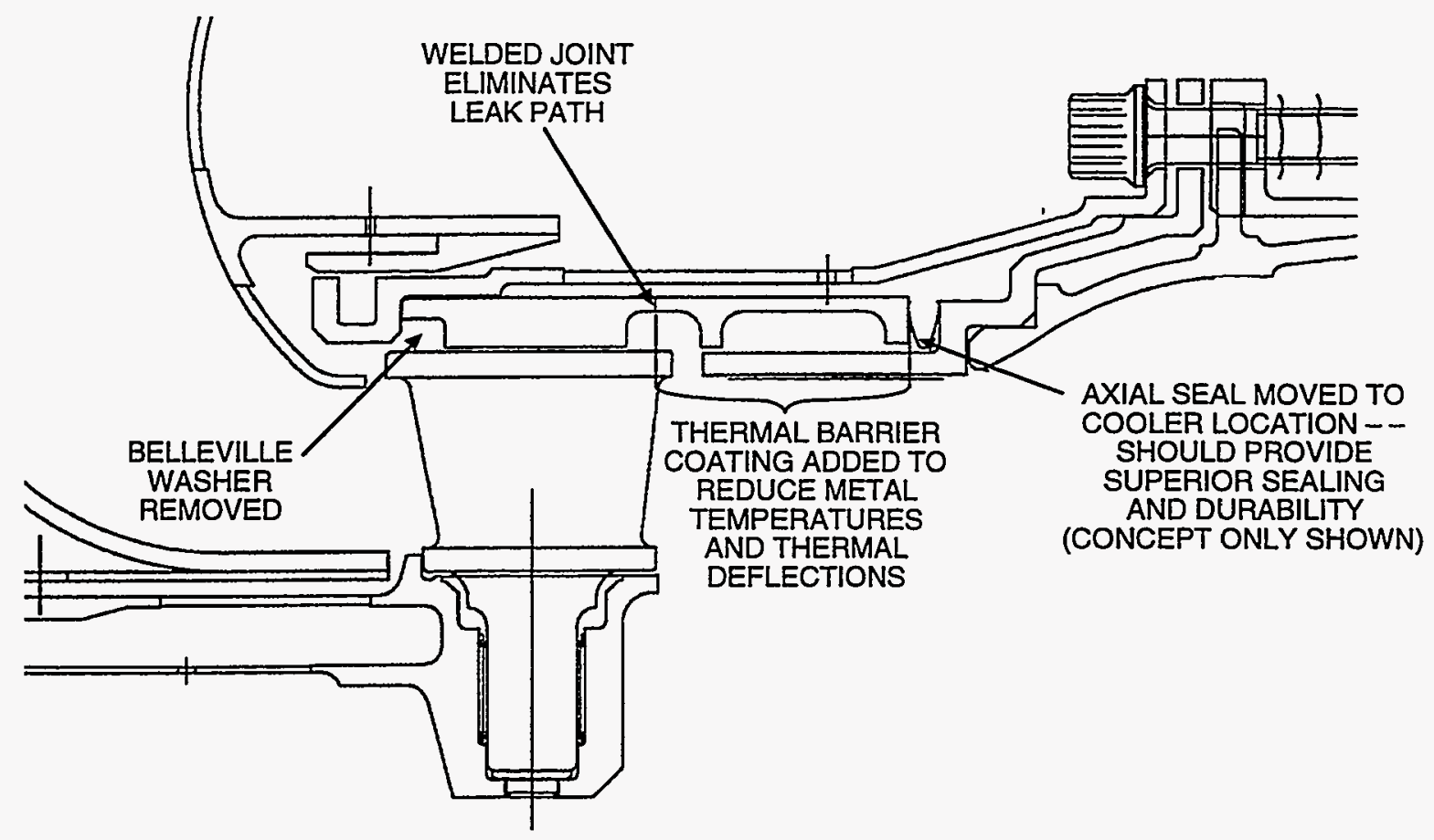

GC12089-14

\section{Figure 14. Modifications To The Engine Outer Structure Were Accomplished, To Enhance Sealing And Reduce Thermal Deflections.}

Ongoing structure design activities that will carry over into 1994 were primarily associated with the nozzle redesign (described in section 3.2). These continuing efforts are indicated in Figure 15 and summarized as follows:

- Nozzle support changes required to accommodate nozzle design changes

- Incorporation of new sealing features to reduce leakage between the ceramic nozzles and the support

- Integration of the OD structure components to reduce the number of leakage paths

- Changes in the location and type of axial seal from the Belleville seal at the forward end of the stack to a conventional " $\mathrm{C}$ " or similar type seal at the aft end of the stack, to reduce temperature and thus, the potential for creep.

The design details and drawings for the redesigned engine structure are planned for completion in the second quarter of 1994. 


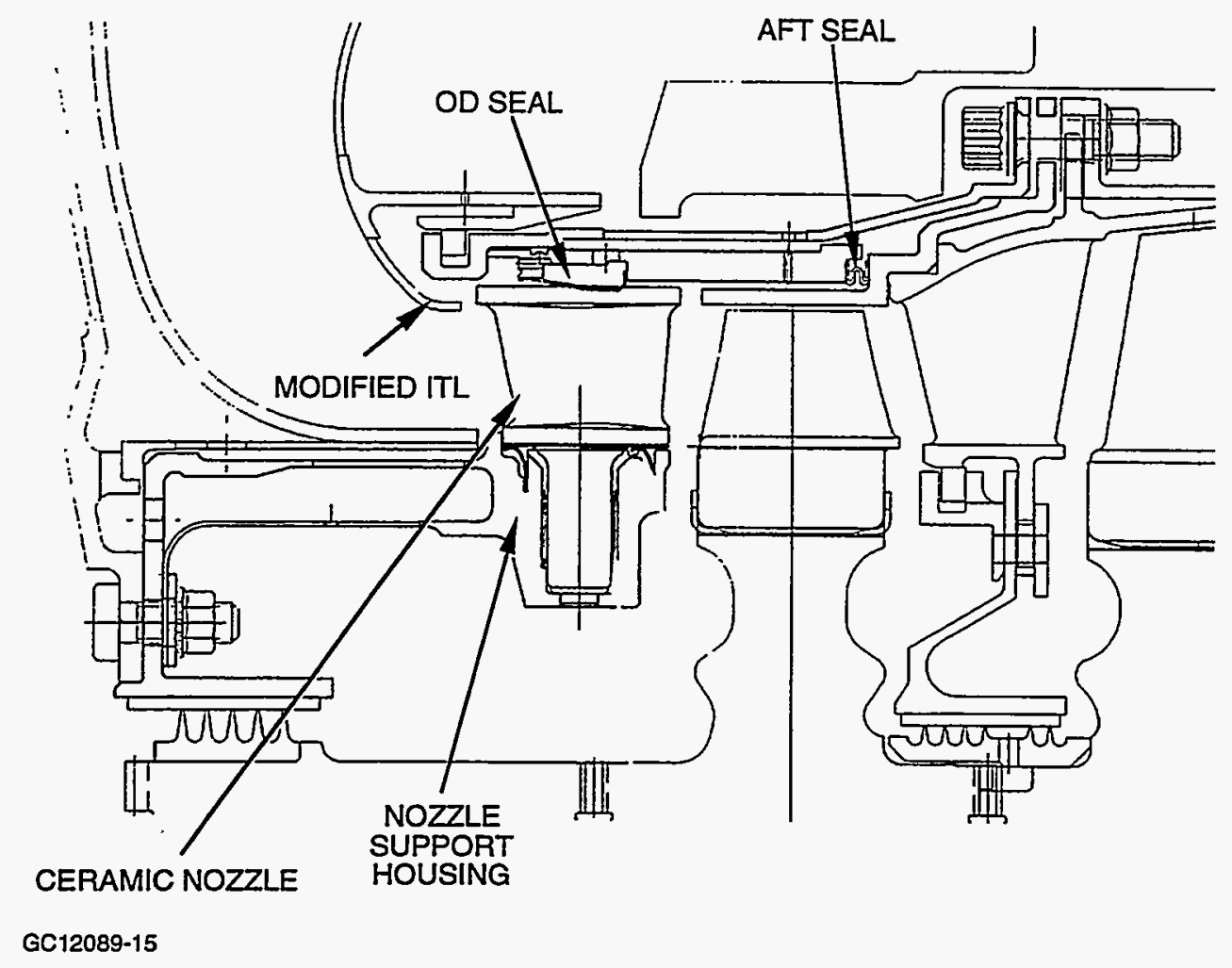

Figure 15. Engine Structure Design Improvements Are Continuing. 


\subsection{COMPONENT FABRICATION}

Norton Advanced Ceramics (NAC), with production facilities located in Northboro, MA and East Granby, CT is the sole vendor selected to supply the 331-200[CT] ceramic turbine blades. The ATTAP/331-200 blades are made of NT154 silicon nitride, pressure slip cast (PSC) to net shape, and hot isostatic press (HIP) densified. The dovetails and shroud contours are machined on the finished part(s). The quality of the delivered parts is expected to be consistent with that of other production aerospace components. A finished ceramic turbine blade is shown in Figure 16.

AlliedSignal Ceramic Components (CC), Torrance, $\mathrm{CA}$ is the vendor selected to provide the 331200[CT] ceramic turbine nozzles. These parts are made by either cold isostatically pressing (CIPping) or pressure slip casting (PSC) of GN-10 silicon nitride blanks, bisque machining of the net shape components from the blanks, HIP densification, and then grinding the attachment/sealing surfaces to final dimensions. As with the ceramic turbine blades, the quality of the nozzles is also expected to be consistent with other production aerospace components. A completed ceramic nozzle segment is shown in Figure 17.

A quantity of 100 blades and nozzles each were ordered. From these orders, a total of 61 blades and 25 nozzles were accepted in 1993 for engine and rig testing. However, none of these parts fully met the quality expectations, though they were judged adequate for short-term demonstration testing. The remaining parts on these orders were rescheduled for delivery during 1994. Future shipments are expected to meet all of the requirements of the component drawing specifications, and to be suitable for the planned longer-duration engine tests.

An order for 100 additional nozzles was placed with NAC. However, it was determined that the current nozzle design was not manufacturable using the NAC net-shape, PSC process. A revised design was initiated at the end of the year which incorporates the proper draft needed to accommodate the slip casting process. NAC ceramic nozzle segment fabrication will be restarted in 1994 using the new design. 


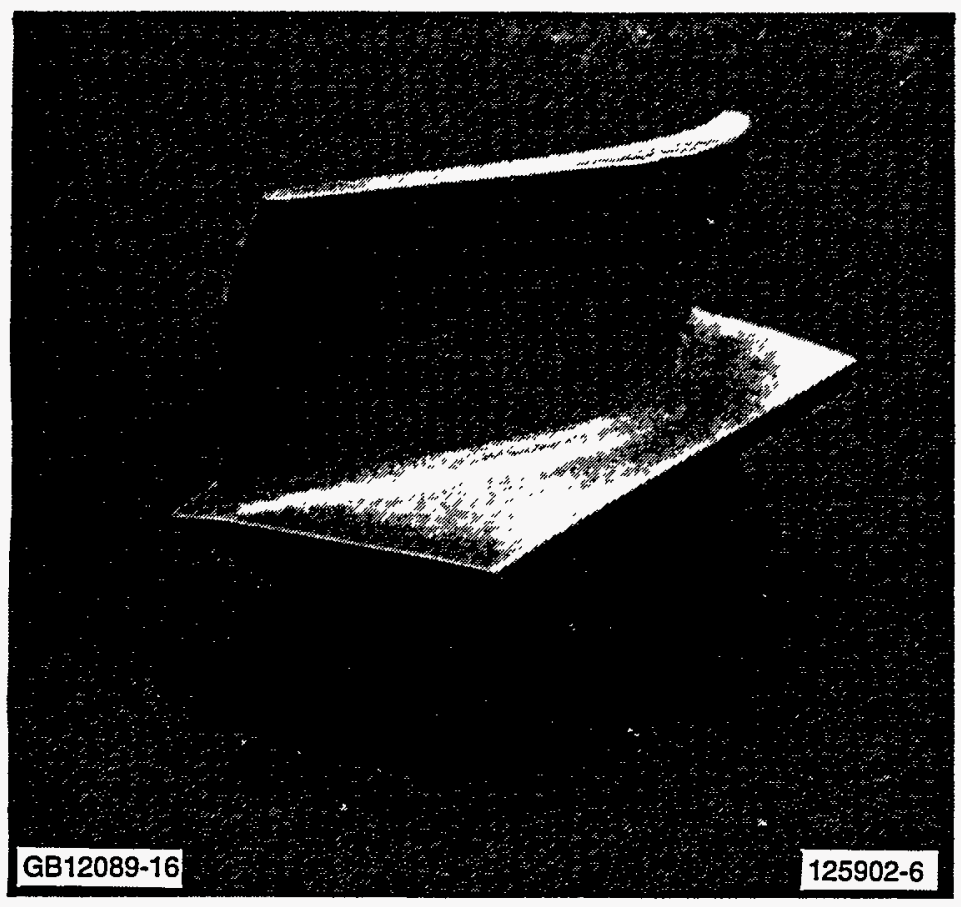

Figure 16. ATTAP/331-200[CT] Ceramic Turbine Blade (Norton Advanced Ceramics NT154 Silicon Nitride).

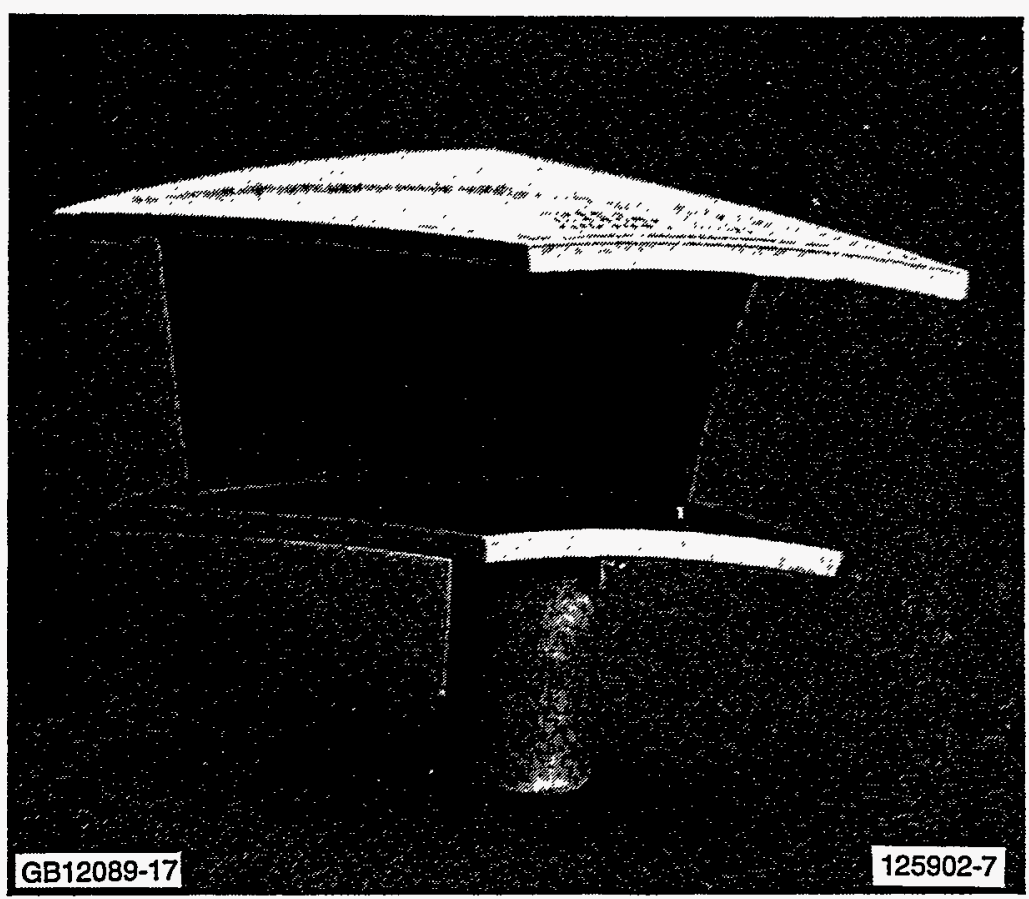

Figure 17. ATTAP/331-200[CT] Ceramic Nozzle Segment (AlliedSignal Ceramic Components GN-10 Silicon Nitride). 


\subsection{COMPONENT TESTING}

The purpose of the planned blade and nozzle component testing was to confirm the design characteristics of these components and to ensure the mechanical integrity of the ceramic blades and

turbine nozzles prior to engine testing. This work included static vibration (acoustic ring signature) testing of the ceramic blades, whirlpit overspeed proof tests of the ceramic blades, airjet impingement testing of the ceramic blades, design of a ceramic nozzle proof test rig, and proof testing of the ceramic nozzles. These activities are discussed in more detail in the following sections.

\subsection{Blade Component Testing}

Acoustic ring signature testing was used to determine the resonant frequency responses of the ceramic blades. In the test, the blade is excited by tapping it with a small hammer. This impact excites all possible blade vibration frequencies, generating an acoustic signature which is measured using a microphone and displayed and analyzed with computer equipment, showing the vibration spectrum. All of the ceramic blades were acoustically tested prior to installation in the test engine.

The testing was performed on the unrestrained blades to measure the free resonant vibration condition. The predicted value of blade resonance in this condition is $34,500 \mathrm{~Hz}$. The average blade response was $33,218 \mathrm{~Hz}$. The range of the test results was 33,750 to $32,375 \mathrm{~Hz}$ and the standard deviation was $378.8 \mathrm{~Hz}$.

\subsection{Blade And Rotor Proof Testing}

The ceramic blades were qualified for engine testing in spin tests (Figure 18) by exposing them to an overspeed condition of $50,000 \mathrm{rpm}$, which is 125 percent of the maximum engine operating speed. This test produces approximately 156 percent of the maximum predicted stress in the neck of the blade attachment.

A total of 88 spin tests were performed on 62 ceramic blades. Some of these tests were retests because of hand finishing work performed on the blades after the initial testing. 


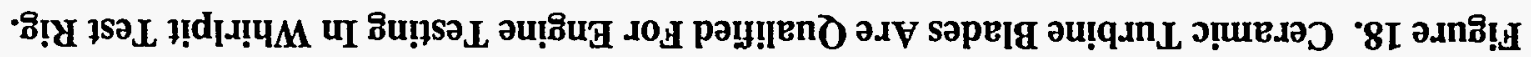

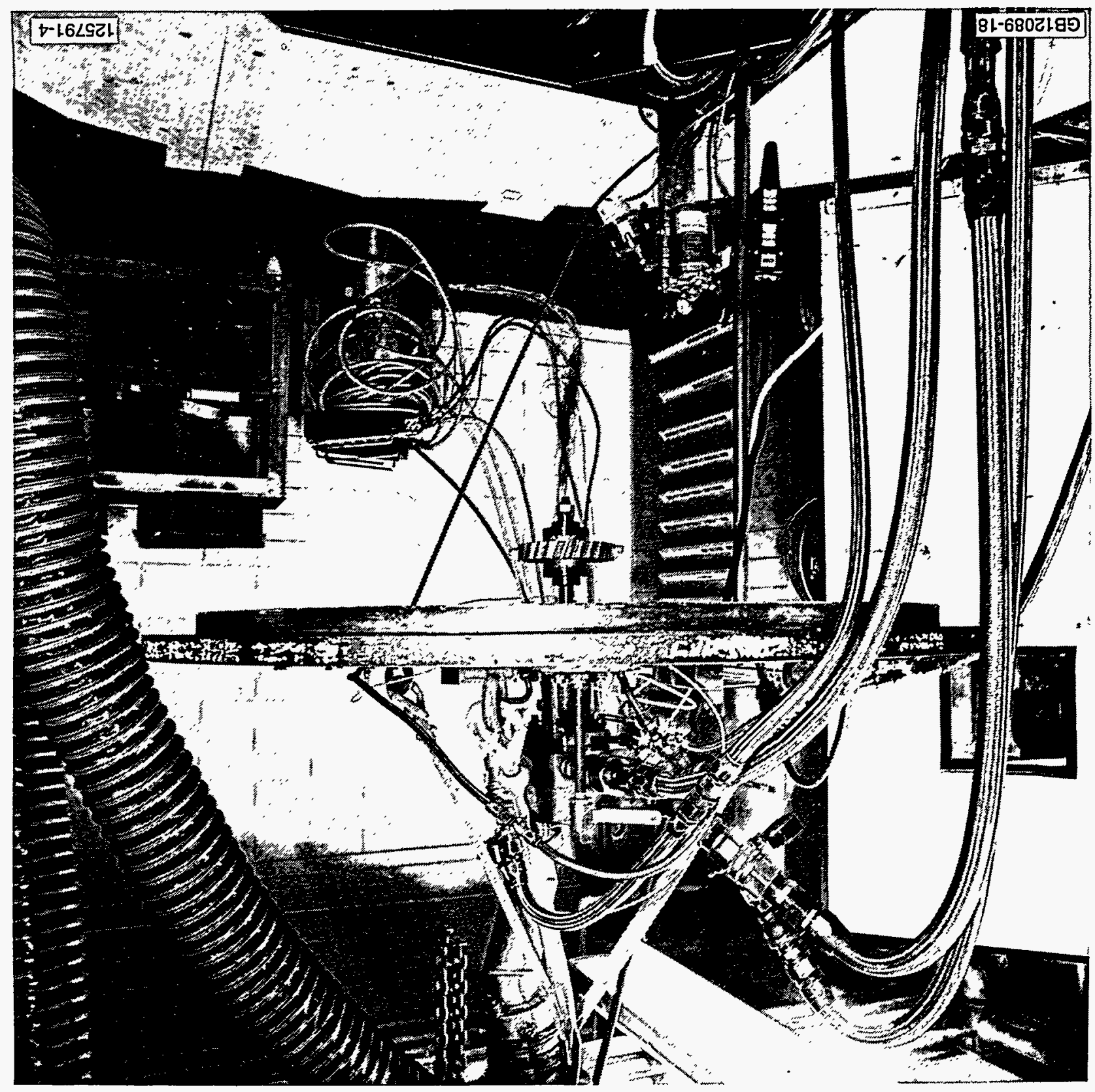




\subsection{Blade Airjet Impingement Testing}

Airjet impingement testing of the ceramic blades was performed to identify blade resonant frequencies with the ceramic blades installed in the metallic turbine disk during rotation. This testing was performed in an evacuated whirlpit equipped with air injection nozzles that drive the turbine blades on the spinning rotor into resonance. The number of nozzles and the speed of the rotor determines the exciting frequency. The advantage of the airjet impingement test is that it most closely simulates the boundary conditions at the blade attachment during blade resonance.

In this testing, an engine disk with two ceramic blades was used. The ceramic blades and disk were instrumented with ten strain gages to measure frequency response. A series of runs were made in order to scan the frequency range from 14,000 to $41,000 \mathrm{~Hz}$ for any significant blade responses.

The single blade resonant response identified was at $30,500 \mathrm{~Hz}$. Strain ratios from gages on the blades indicated that this was the first mode. No other resonant modes were identified within the test range of frequencies.

\subsection{Nozzle Proof Testing}

The nozzle proof test rig design is shown in Figure 19. The rig incorporates a sonic nozzle to control airflow, a pipe combustor, and a test section with a removable test module. The rig was designed to simulate the mechanical and thermal stresses the ceramic nozzles experience in the engine. The segments are tested individually, to ensure each component is exposed to the same conditions. The test section, shown in Figure 20, incorporates a standard machine collet for rapid installation and removal of the nozzle segments.

The objective of this activity was to expose the ceramic nozzles to conditions more severe than in the engine. As shown in Figure 21, the test rig imposes a step temperature change in the inlet air to the test piece, and is capable of imposing a temperature transient of $2400 \mathrm{~F}(1316 \mathrm{C})$ in less than one second on the nozzle, while a production 331-200 engine may take up to 18 seconds to reach the same temperature.

The test rig was used to qualify a set of ceramic nozzles for the initial ceramic nozzle equipped engine test. These nozzles were exposed to rig cycles with a peak temperature of $2600 \mathrm{~F}$ (1427C). All 35 nozzles passed this test. From this lot, 23 parts were selected for use in the first engine test. 


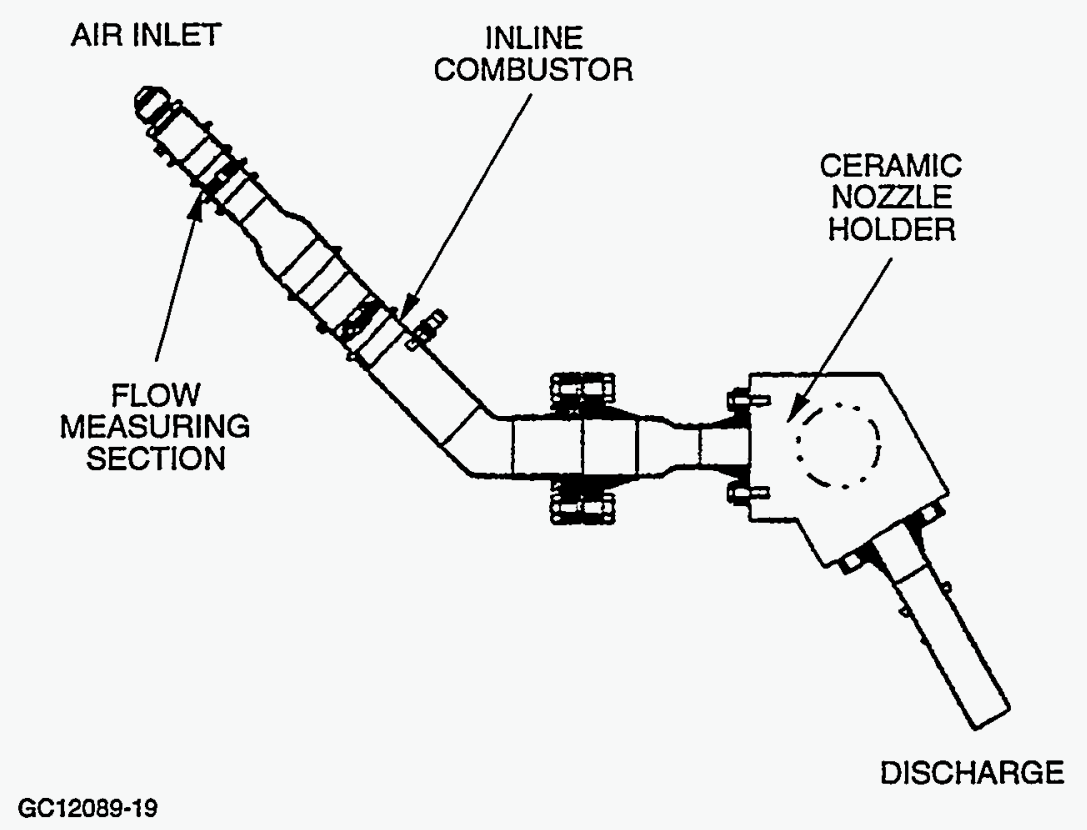

Figure 19. Ceramic Nozzle Proof Test Rig Is Designed To Simulate Engine Stresses.

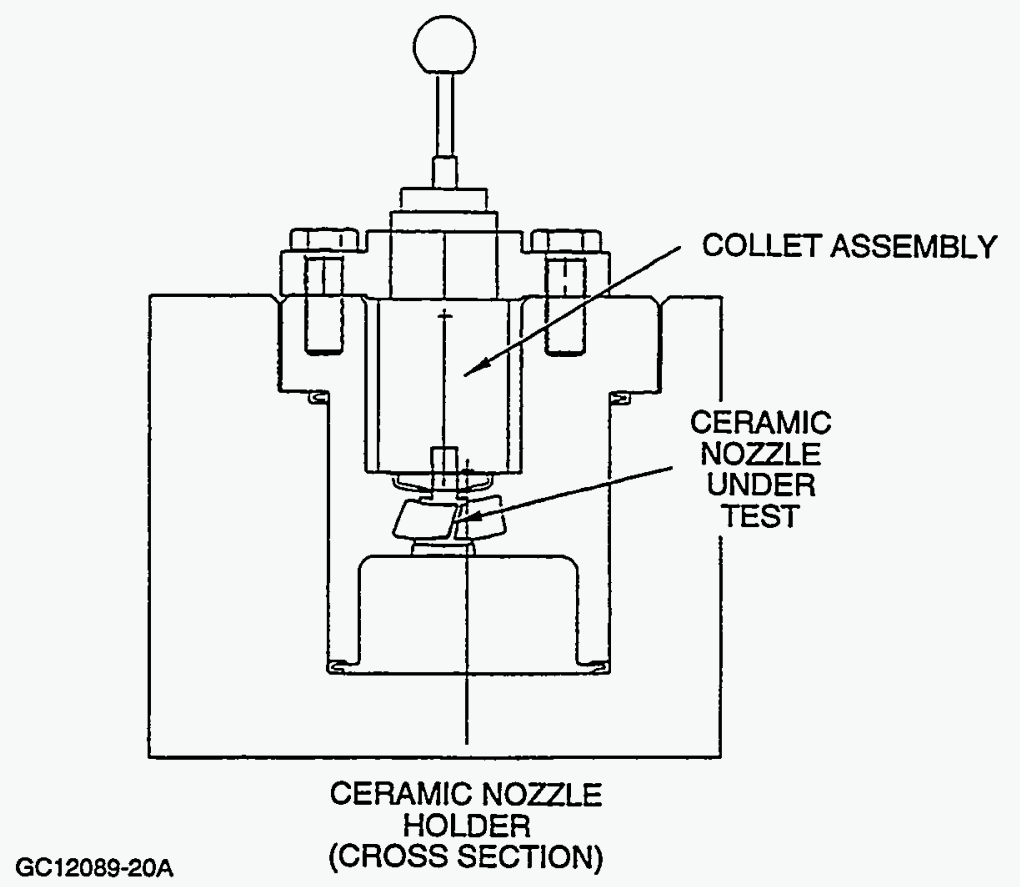

Figure 20. Nozzle Proof Test Section Incorporates A Standard Machine Collet For Rapid Installation And Changeout Of Nozzle Segments. 


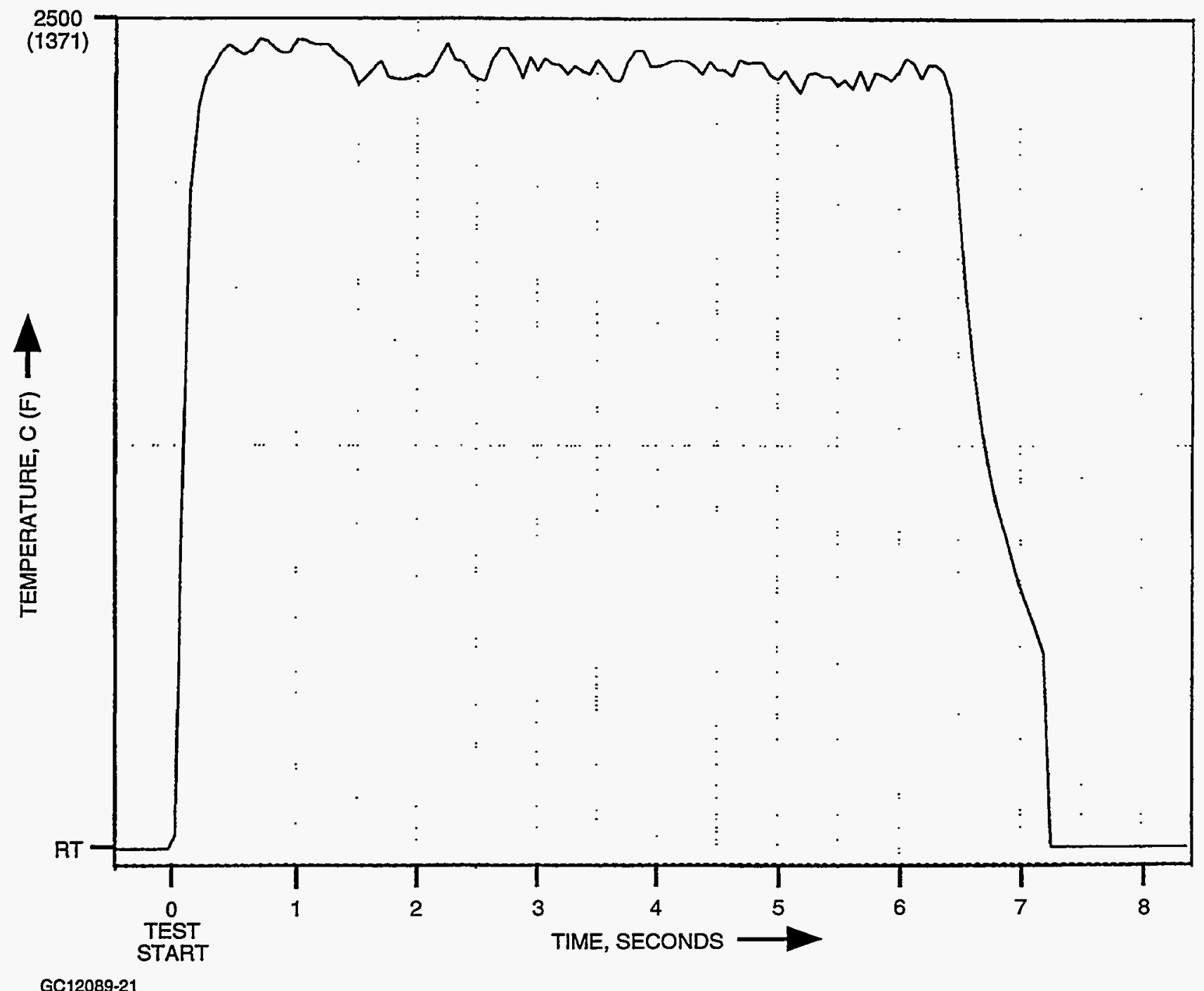

Figure 21. Ceramic Nozzle Proof Test Conditions Are More Severe Than Those Seen In Engine Operation. 


\subsection{CERAMIC TECHNOLOGIES AND METHODS}

The design technologies and methods for critical gas turbine components made from ceramic materials require additional refinement in several areas. A number of technologies were addressed in 1993 under this program. Progress in these technologies is discussed in the following paragraphs.

\subsection{Ceramic Blade Attachment}

The goal of the ceramic blade attachment enabling technology program is to provide the mechanical designer with directly applicable design data and methods to ensure the most robust and efficient inserted turbine blade designs.

Activity in the first half of 1993 primarily consisted of re-evaluating and re-establishing the program direction from a predominantly component testing orientation, to a program with specimen testing to characterize ideal design limits of key parameters, followed by subelement testing to verify and provide the link between specimen testing and actual hardware.

Definition of the specimen test matrix was completed in the third quarter of 1993 . The test matrix is shown in Table 2. Specimens and test fixtures were ordered and received, and initial test methods development was initiated. The specimen testing will be performed on the existing ATTAP contact test rig (shown in Figure 22).

\subsection{NDE Reliability}

The overall objective of the nondestructive evaluation (NDE) reliability effort is to quantify the probability of detection (POD) of existing NDE methods for internal flaws in ceramics. For 1993 the primary objective was to begin characterization of the types of intemal defects inherent in the ceramic fabrication process. This work examined flawed ceramic specimens using radiography.

The specimens consisted of rejects from the normal fabrication processes for scheduled ceramic engine hardware deliveries. A total of 76 ceramic components were collected from the ceramics suppliers, which had processing completed, but were defective in some respect. Inspection was begun on these components to characterize the volume flaws, with radiographic inspection completed on 30 components by the end of the year. In addition, radiographic inspection to characterize flaws was completed on 445 additional ceramic test specimen bars. 
TABLE 2. CERAMIC TURBINE BLADE ATTACHMENT SPECIMEN TEST MATRIX

\begin{tabular}{|l|c|c|c|c|c|}
\hline \multicolumn{5}{|c|}{ BASELINE TEST MATRIX } \\
\hline \multicolumn{7}{|c|}{ Parameter } & $\begin{array}{c}\text { Room } \\
\text { Temperature }\end{array}$ & $\begin{array}{c}\text { 1300F } \\
\text { (704C) }\end{array}$ & Cyclic & $\begin{array}{c}\text { Dwell } \\
\text { Time }\end{array}$ & Sliding \\
\hline \hline Flexure strength & 20 & 20 & -- & -- & -- \\
\hline Normal contact stress & 10 & - & -- & -- & -- \\
\hline $\begin{array}{l}\text { Tangential contact stress } \\
\text { a. Tan/norm = C1 } \\
\text { b. Tan/norm = C2 }\end{array}$ & 15 & 5 & 5 & 5 & 5 \\
\hline Background stress & 5 & 5 & -- & -- & -- \\
\hline
\end{tabular}

\begin{tabular}{|l|l|c|c|c|c|}
\hline \multicolumn{6}{|c|}{ COMPLIANT LAYER TEST MATRIX } \\
\hline \multicolumn{7}{|c|}{ Parameter } & $\begin{array}{c}\text { Room } \\
\text { Temperature }\end{array}$ & $\begin{array}{c}\mathbf{1 3 0 0 \mathrm { F }} \\
\mathbf{( 7 0 4 C )}\end{array}$ & Cyclic & $\begin{array}{c}\text { Dwell } \\
\text { Time }\end{array}$ & Sliding \\
\hline \hline Flexure strength & -- & - & -- & -- & -- \\
\hline Normal contact stress & 10 & -- & -- & -- & -- \\
\hline $\begin{array}{l}\text { Tangential contact stress } \\
\text { a. Tan/norm = C1 } \\
\text { b. Tan/norm = C2 }\end{array}$ & 15 & 5 & 5 & 5 & 5 \\
\hline Background stress & 5 & 5 & -- & - & -- \\
\hline
\end{tabular}

\begin{tabular}{|l|c|c|c|c|c|}
\hline \multicolumn{7}{|c|}{ TOLERANCE EFFECTS } \\
\hline \multicolumn{1}{|c|}{ Parameter } & $\begin{array}{c}\text { Room } \\
\text { Temperature }\end{array}$ & $\begin{array}{c}\mathbf{1 3 0 0 F} \\
\mathbf{( 7 0 4 C )}\end{array}$ & Cyclic & $\begin{array}{c}\text { Dwell } \\
\text { Time }\end{array}$ & Sliding \\
\hline \hline Flexure strength & -- & -- & -- & -- & -- \\
\hline Normal contact stress & -- & -- & - & -- & -- \\
\hline Tangential contact stress & 15 & 5 & 5 & 5 & - \\
a. Tan/norm = C1 \\
b. Tan/norm = C2
\end{tabular}

\begin{tabular}{|l|c|c|c|c|c|}
\hline \multicolumn{7}{|c|}{ SURFACE STRENGTH } \\
\hline \multicolumn{1}{|c|}{ Parameter } & $\begin{array}{c}\text { Room } \\
\text { Temperature }\end{array}$ & $\begin{array}{c}\mathbf{1 3 0 0 \mathrm { F }} \\
\mathbf{( 7 0 4 C )}\end{array}$ & Cyclic & $\begin{array}{c}\text { Dwell } \\
\text { Time }\end{array}$ & Sliding \\
\hline \hline Flexure strength & 20 & 20 & - & -- & -- \\
\hline Normal contact stress & -- & -- & -- & -- & -- \\
\hline $\begin{array}{l}\text { Tangential contact stress } \\
\text { a. Tan/norm = C1 }\end{array}$ & 15 & 5 & 5 & 5 & 5 \\
\hline Background stress & -- & -- & -- & -- & -- \\
\hline
\end{tabular}



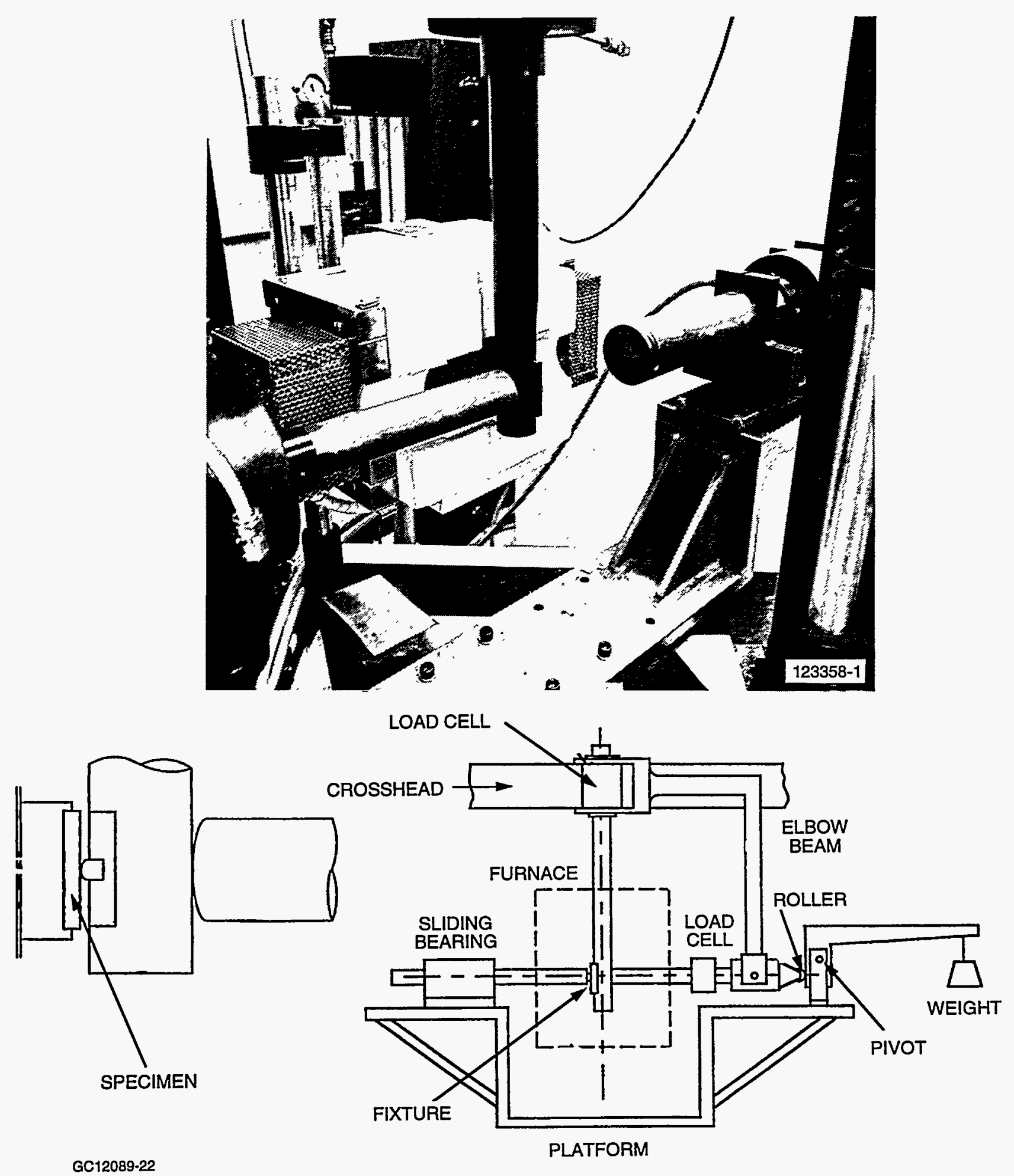

Figure 22. Ceramic Blade Attachment Specimen Testing Will Be Performed Using The Existing ATTAP Contact Test Rig. 


\subsection{Ceramic Oxidation And Hot Corrosion}

Testing conducted in the ATTAP program has demonstrated that hot corrosion attack can adversely affect the strength of silicon nitride $\left(\mathrm{Si}_{3} \mathrm{~N}_{4}\right)$ in the 850 to $1300 \mathrm{C}$ (1562 to $2372 \mathrm{~F}$ ) temperature range. Tests were conducted under the conditions listed in Table 3. The tests included flexure strength testing at room temperature to measure retained strength following exposure.

TABLE 3. OXIDATION AND HOT CORROSION EXPOSURE TEST CONDITIONS.

\begin{tabular}{|ll|}
\hline Temperature & 860 to $1288 \mathrm{C}(1580$ to $2350 \mathrm{~F})$ \\
Pressure & 1 to $5 \mathrm{~atm}$ \\
Sea Salt in Combustion Air & 2 to $10 \mathrm{ppm}$ \\
Exposure Time & 1 to $3300 \mathrm{hr}$ \\
\hline
\end{tabular}

The test data indicates that salt exposure at temperatures above $860 \mathrm{C}(1580 \mathrm{~F})$ resulted in very rapid and significant strength loss of the silicon nitride specimens. This deterioration persisted over a very broad range of temperatures and operating pressures. Exposure at $860 \mathrm{C}(1580 \mathrm{~F})$ showed less severe loss in strength, and the material retained usable strength following exposures up to 3300 hours.

Figure 23 indicates the nature of the material strength loss. Surface recession of the silicon nitride specimens exposed at temperatures below $900 \mathrm{C}(1652 \mathrm{~F})$ progressed at relatively low rates, although the specimen surfaces were roughened from corrosive action. Above $900 \mathrm{C}(1652 \mathrm{~F})$, surface recession rates increased to significant levels, where material loss in addition to surface roughening contributed to the loss in retained strength.

A mechanistic model (Figure 24) was generated to predict the loss in retained strength of silicon nitride after exposure to sea salt at elevated temperatures. The model was calibrated with data from specimens exposed at 1 atmosphere (atm) pressure and 5 parts per million (ppm) sea salt in the combustion air. The model was then used to predict the strength loss for silicon nitride specimens exposed to a range of conditions from 1 to $5 \mathrm{~atm}$ pressure and 2 to $10 \mathrm{ppm}$ salt concentration. The model predictions are compared with test data in Figure 25. This graph shows that the model accurately predicts the average retained strength over the range of pressures and salt concentrations tested. However, considerations for data scatter need to be addressed. 


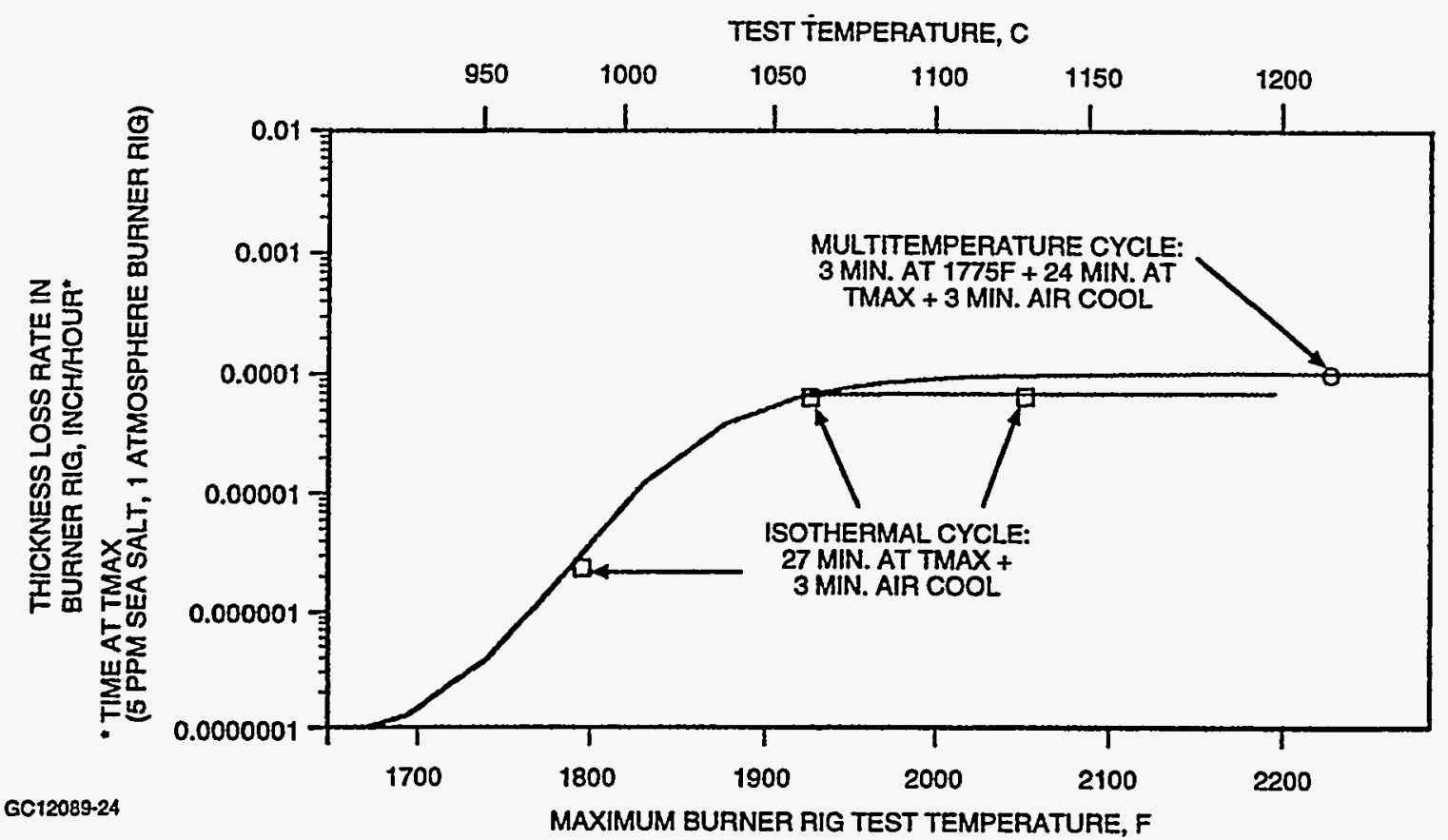

Figure 23. Hot Corrosion Attack Reduced Thickness Of NT154 Silicon Nitride Strength Test Specimens In Exposures Above 900C (1652F).

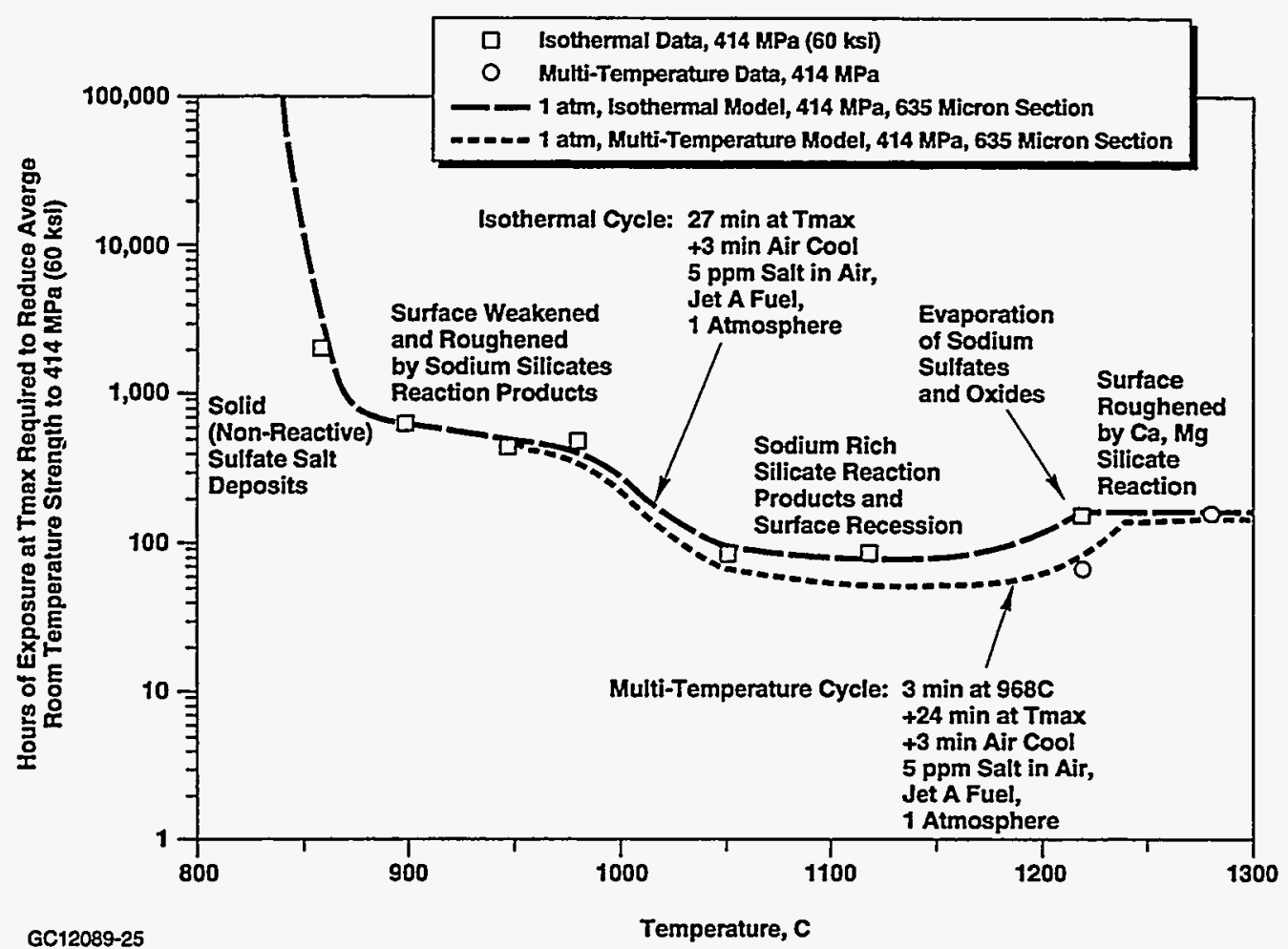

Figure 24. Mechanistic Model Predicts Environmental Life (Strength Retention) Of NT154 Silicon Nitride Exposed To Hot Corrosion Environment. 


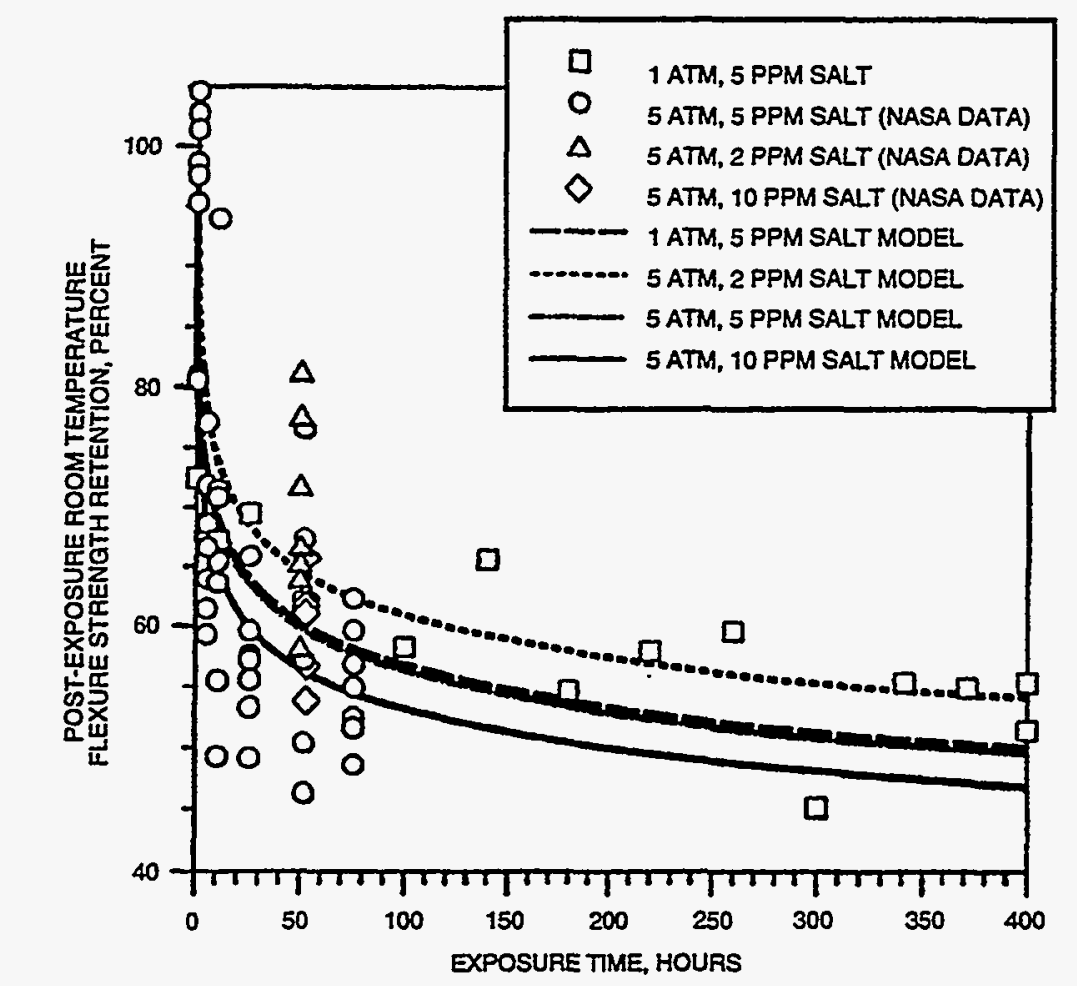

GC12009-26A

Figure 25. Comparison Of Ceramic Environmental Life Model Predictions With Hot Corrosion Test Results Shows Surface Strength Reduction Is Sensitive To Exposure Time And Severity Of The Burner Rig Test Environment.

Flexure strength retention (including the effects of surface recession) was modeled as a function of the severity of the hot corrosion environment and the results were used to calibrate the life prediction model, illustrated in Figure 24 for isothermal and multi-temperature burner rig test conditions. Preliminary predictions from the model indicate a strength reduction in machined NT154 surfaces to less than $60 \mathrm{ksi}(414 \mathrm{MPa})$ after a relatively short exposure to hot corrosion. The capability of the model to predict NT154 silicon nitride component strength retention life was demonstrated. The model can predict component life based on functions of engine design parameters (stress, temperature, pressure, fuel/air ratio, gas velocity, and inlet air filtration), mission usage (fuel sulfur content, location [salt in the air], and time at duty cycle power points), and ceramic material properties. Figure 26 shows a typical plot produced from the model for a selected set of parameters. Further work is continuing to study the relationship between the effects of the engine operating environment on ceramic strength and the effects noted in the environmental exposure test rigs. 


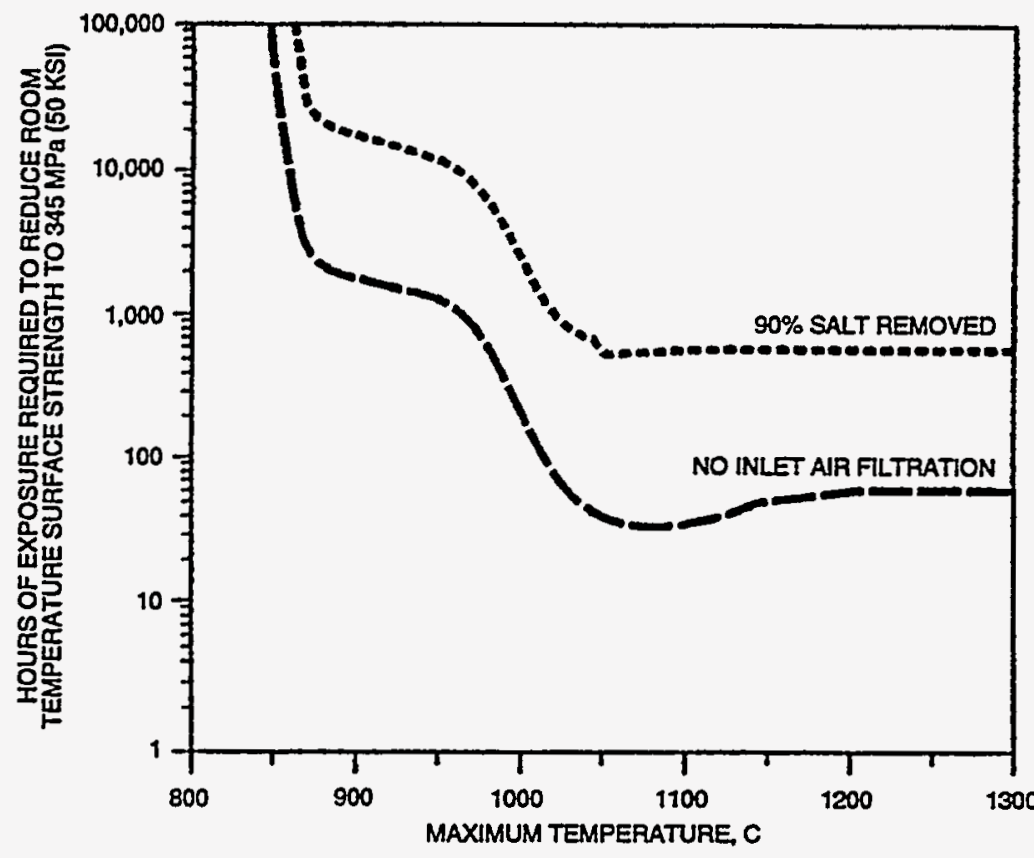

FUEL: JET A ( $0.035 \%$ SULFUR)

FUEL LAIR RATIO: 0.02

GAS VELOCTYY: 850 FT/SEC

LOCATION: COAST

ALTITUDE: SEA LEVEL

PRESSURE AT MAX POWER: 10 ATM

TMME AT MAX POWER: $90 \%$

PRESSUREAT IDLE: 5 ATM

TIME AT IDLE: $10 \%$

IDLE TEMP = MAX POWER TEMP $\angle 000$

IDLE TEMP $=900 \mathrm{C}$ FOR MAX POWER TEMP $>9000$

SECTION THICKNESS $=0.025 \mathrm{INCH}$

GC1208940

Figure 26. Typical Silicon Nitride Component Environmental Life Plot For Selected Parameters.

\subsection{Impact Design Methods}

The objectives of the ceramic impact resistance design technology work are to 1) improve the accuracy of the impact design methods by incorporating a material model simulating carbon pulverization during impact, and 2) establish a functional relationship between axial inserted blade design variables and impact resistance (failure velocity) to guide ceramic blade design efforts.

The carbon pulverization model under development is expected to provide realistic blade impact stresses from impact finite element $(\mathrm{FE})$ analyses. An inelastic impact particle material model and model parameters were identified previously in the ATTAP program that accurately predicted the strain time response measured in actual ceramic specimens impacted with carbon particles. Three-dimensional (3-D) FE models were created for two ceramic impact-resistant blade designs, and were successfully used to calculate the surface strength of NT154 silicon nitride subelement blade specimens which were tested to failure in an Instron load test machine system. Both blade designs exhibited surface strengths of $86 \mathrm{ksi}$ (593 MPa), which is typical of NT154 as-processed surfaces.

The FE models were then updated, and a carbon projectile model was included for use in the impact analyses. These models are being used to confirm the carbon pulverization material model. 


\subsection{ENGINE TESTING}

Engine operational testing was conducted with the 331-200[CT] test bed to demonstrate the design integrity of the ceramic blades and nozzles. Figure 27 shows the test bed engine installed in the test cell. In this work, the ceramic turbine nozzles were evaluated in a test engine equipped with metallic blades and the ceramic turbine blades were evaluated in an engine equipped with metallic nozzles. Through these separate test evaluations, the initial development risk was reduced for both components. The following paragraphs summarize the engine testing performed during 1993 on each of the ceramic components.

\subsection{Ceramic Nozzle Engine Testing}

A series of three tests of the ceramic nozzle equipped engine was performed. The first was a test of the engine control systems, in which a series of controlled start cycles was developed for use in the initial tests of the ceramic nozzles. This was followed by a series of tests using the ceramic nozzles. The first test was conducted to determine the operability limits of the ceramic nozzle equipped engine, and the second test evaluated the engine nozzle structural system in an accelerated mission endurance test simulating over 300 hours of engine operation. The results of these tests are summarized in the following paragraphs:

\subsubsection{Engine Start Cycle Modifications}

To evaluate various engine start cycles, the 331-200[CT] test bed engine was equipped with metallic blades and nozzles and a modified electronic control unit (ECU) and tests were conducted. As a result of this test, ECU configurations were identified to produce five different starts of increasing severity. The easiest start produces a peak turbine inlet temperature (TT) of $1450 \mathrm{~F}$ (788C) at 25 seconds after lightoff. A normal start produces a TIT of $2000 \mathrm{~F}(1093 \mathrm{C})$ at 16 seconds after lightoff. The most severe start combines a normal start with immediate engine loading to maximum power, producing a peak TIT of $2400 \mathrm{~F}(1316 \mathrm{C})$ at 18 seconds after lightoff.

These modifications were used in the initial ceramic nozzle engine testing, because analysis indicated that the peak stress in the nozzle occurs during the start transient (Figure 10) and is a function of the peak start temperature and how quickly it occurs. 


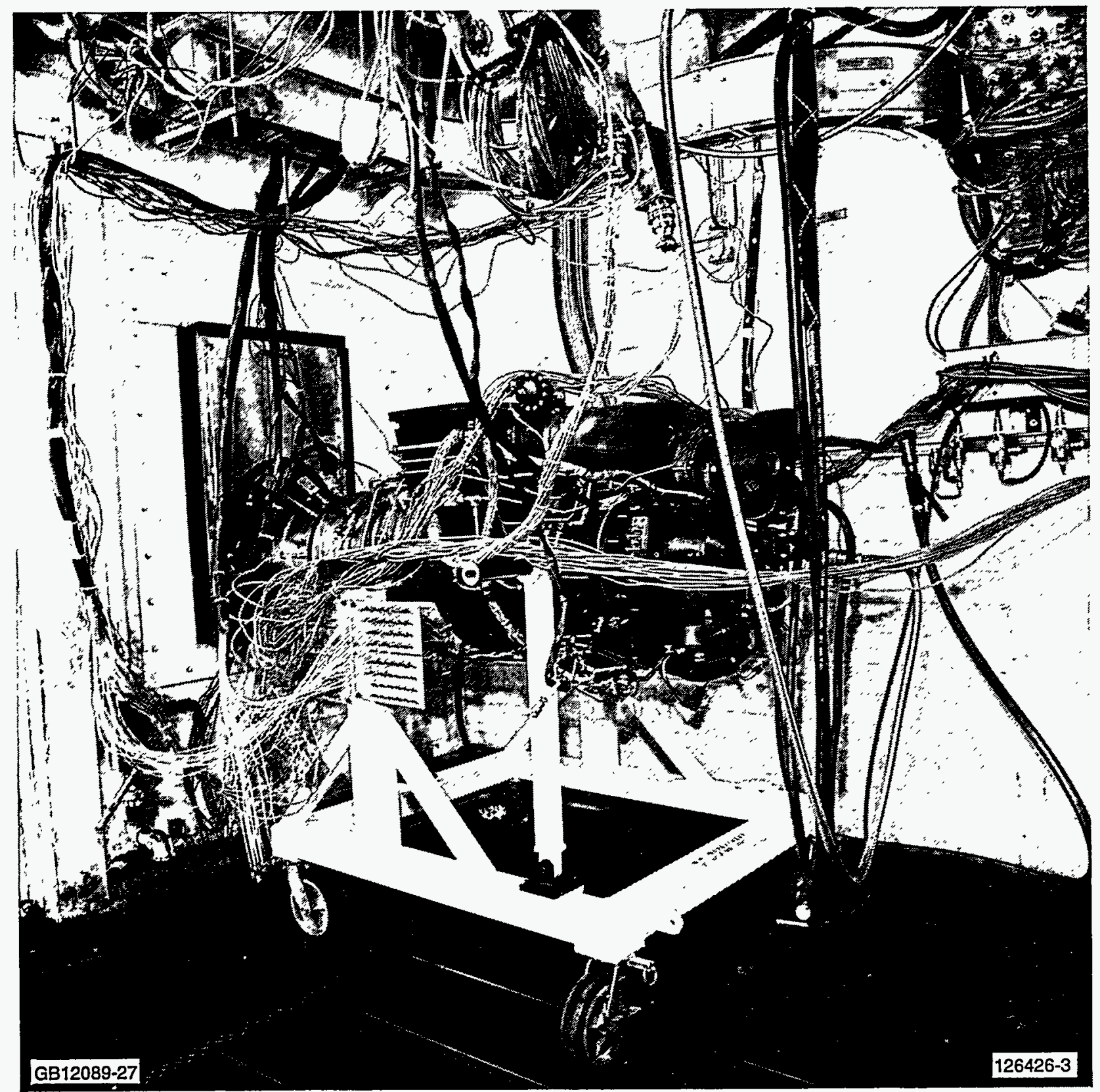

Figure 27. ATTAP/331-200[CT] Test Bed Engine Installed In The Test Cell. 


\subsubsection{Ceramic Nozzle Operability Test}

The objective of the initial ceramic nozzle equipped engine test was to operate the engine over a full range of engine conditions, validate the ability of the ceramic nozzles to withstand a production start, and accumulate ten hours of operating time.

A total of nine starts were performed, which included five "soft" starts, two normal starts with a 50second hold at the "Ready To Load" (RTL) condition, and two severe starts with a normal 50-second startup immediately followed by loading to the "Main Engine Start" (MES) condition. The entire test was completed without incident. A total of 10 hours 15 minutes of testing was completed. Figure 28 shows the undamaged ceramic nozzle assembly following testing and engine disassembly.

Data collected during this test resulted in some minor modifications to the metallic structures surrounding the ceramic nozzles to more effectively control gas leakage and the structure temperatures.

\subsubsection{Accelerated Mission Cycle Test}

The objectives of this test were to validate the redesigned metallic structures, and to complete 100 hours of accelerated durability testing. This test was successfully performed over the full range of 331$200[\mathrm{CT}]$ engine operating conditions, accumulating the following statistics:

- Total run time $=107.75$ hours

- $\quad$ Starts $=312$

- $\quad$ Accelerated duty cycles $=300$

The accelerated duty cycle simulates three times the equivalent engine operating time, or an equivalent total of approximately 300 hours of engine operation.

The ceramic components used in this testing were manufactured by AlliedSignal Ceramic Components from GN-10 silicon nitride. This set of ceramic nozzles has accumulated a total of 118 actual operating hours and 321 starts. 


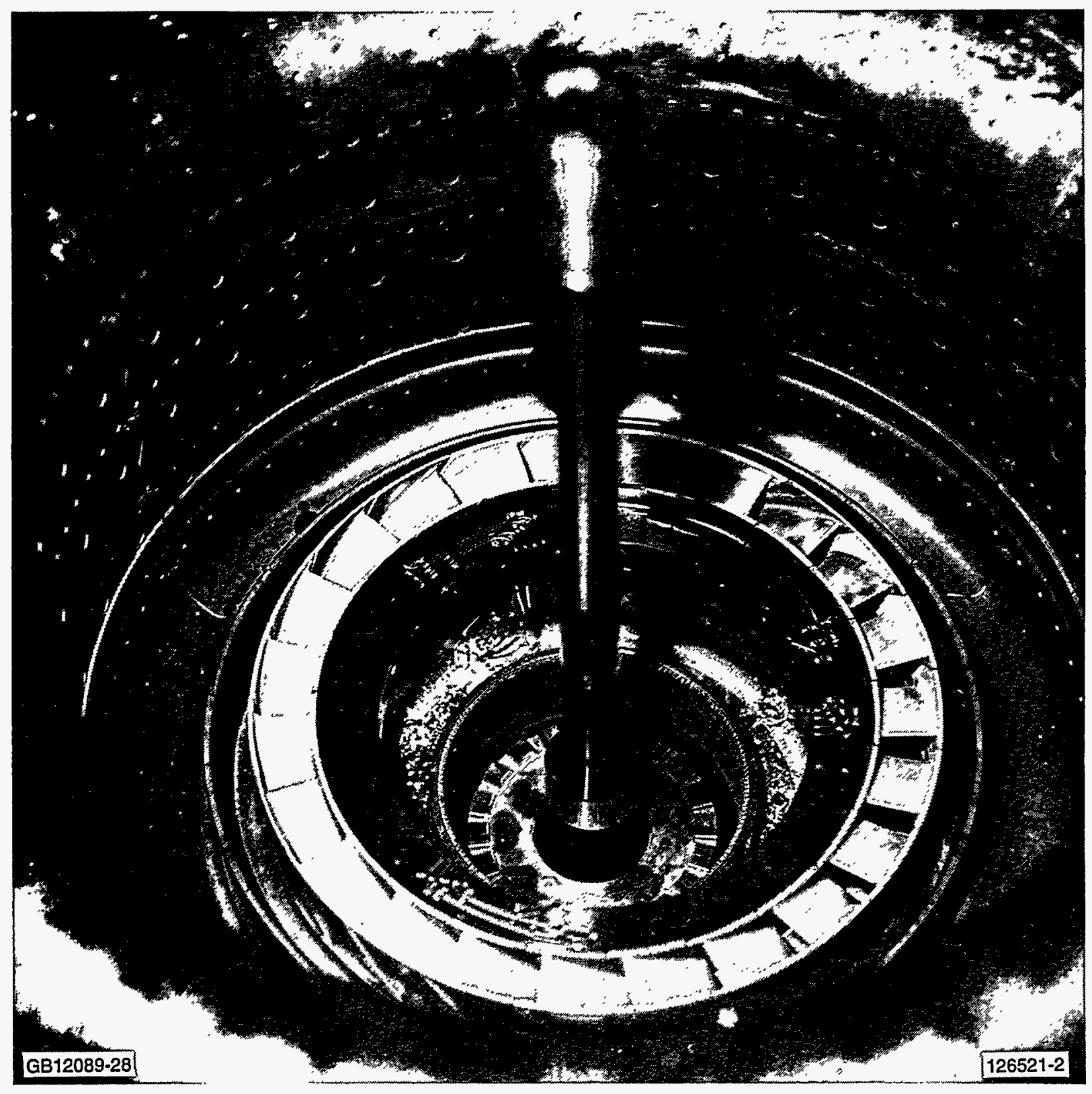

Figure 28. Ceramic Nozzle Assembly Was Undamaged Following Engine Testing. 


\subsection{Ceramic Blade Engine Testing}

The objective of the initial ceramic blade equipped engine test was to operate the engine over the full range of engine conditions, validate the ability of the ceramic blades to withstand a production start, and accumulate ten hours of operating time.

Unfortunately, engine failures occurred during each of the two planned tests, which damaged all of the ceramic blades. Disassembly inspections following the test failures revealed that all of the ceramic turbine blades were broken and the metallic structures around the turbine were distressed. In the first test, the engine failed during the initial start. The most likely cause of the failure was traced to inadequate flatness in the blade attachment zone on the metallic turbine disk. The photograph in Figure 29 shows the localized contact areas found on one of the ceramic blade dovetails following the test.

A second engine build was prepared for testing which incorporated corrective actions identified as a result of the failure investigation following the first test. All of the engine structures damaged in the first test were repaired or replaced and reinstrumented as required for resumption of the ceramic blade equipped engine testing. A metallic turbine disk was also specially prepared and inspected to ensure that the blade attachment features had the proper flatness.

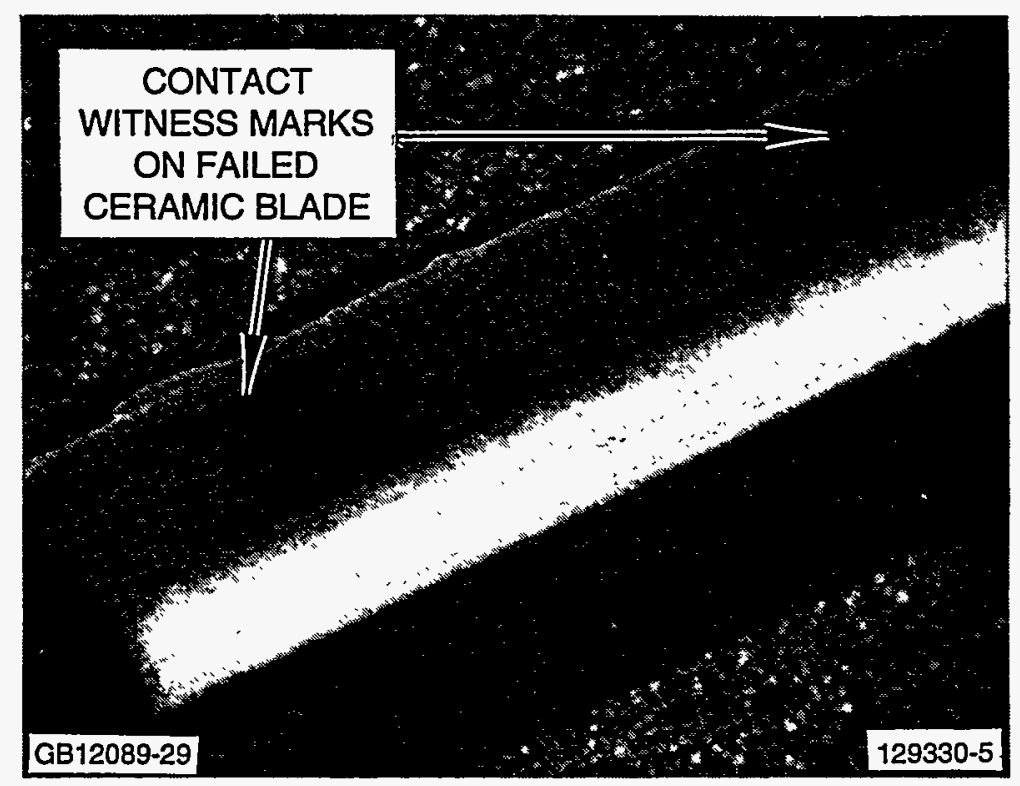

Figure 29. Localized Contact Areas Were Noted On Ceramic Blade Dovetail Following First Ceramic Blade Equipped Engine Test Failure. 
The second engine build successfully completed three production starts, accumulating 1 hour 11 minutes operating time before a turbine section failure occurred. This engine build had successfully operated over the full range of 331-200[CT] engine conditions prior to the failure. The failure occurred 16 seconds after the engine was unloaded from the MES to the RTL operating condition. The engine completed 51 minutes operation at RTL, 10 minutes at the "Environmental Control System" (ECS) operating condition, and 10 minutes at MES.

The failure investigation completed on the second ceramic blade equipped engine test established that the most likely cause of engine failure was vibration in the ceramic turbine blades; however, contributing thermally-induced contact stress could not be ruled out. At the end of 1993, work was being performed to determine methods for measuring the blade vibration levels at the engine operating conditions at which the failure occurred. 


\subsection{PROGRAM MANAGEMENT}

The ATTAP/331-200 Ceramic Demonstration Program efforts were initiated on January 4, 1993. Utilizing Total Quality Leadership (TQL) techniques, program direction was provided by the AlliedSignal ATTAP Leadership Team which coordinates the activities of the five technical teams, including Ceramic Technologies, Design, Hardware, Component Testing, and Engine Testing teams, as shown in Figure 30. The administrative activities were performed by the Administration Team, with representatives from the five technical teams and the AlliedSignal Engines Business Management, Data and Documentation Management, and Engineering Resource Management departments.

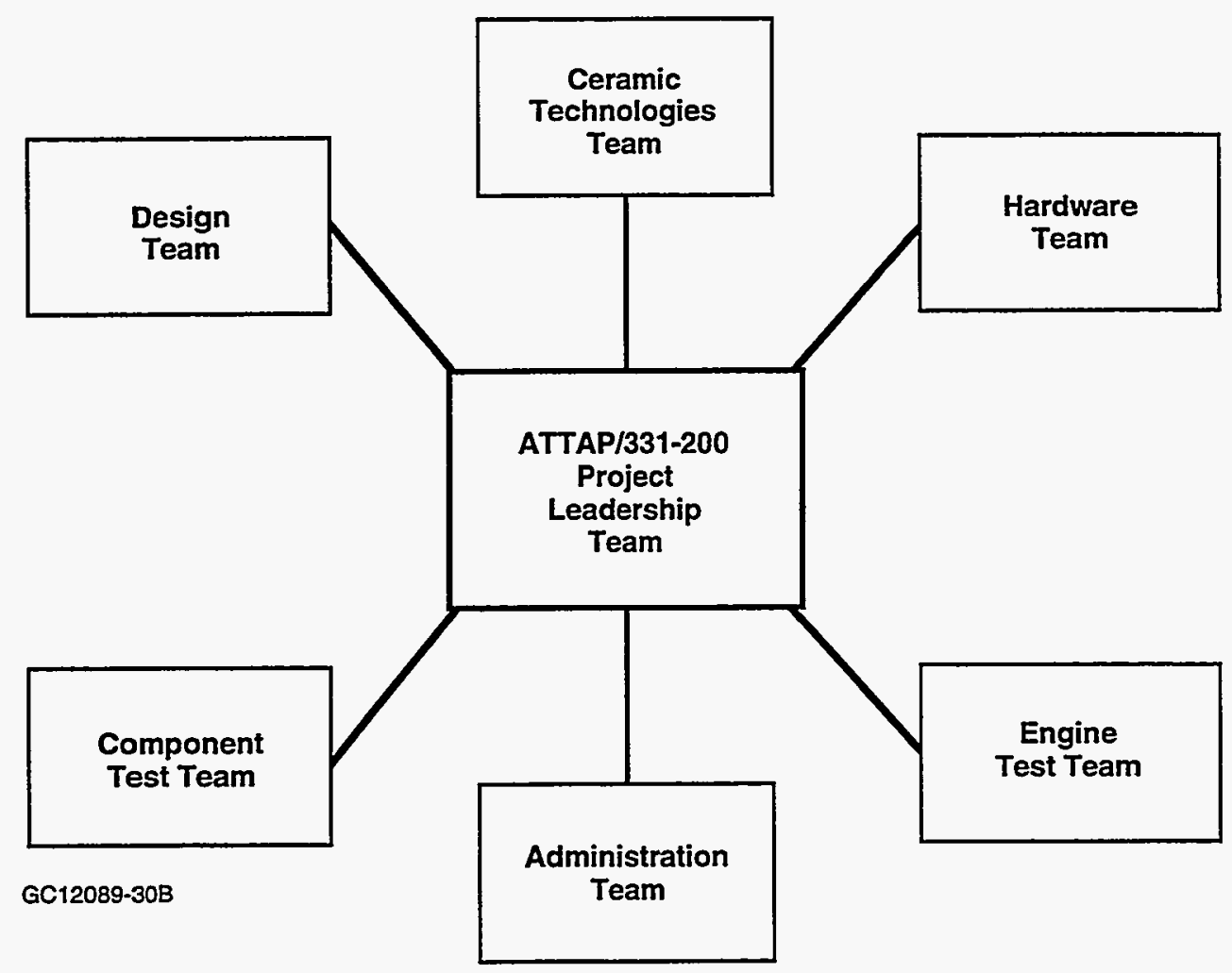

Figure 30. AlliedSignal ATTAP Leadership Team Utilizes Total Quality Leadership (TQL) Techniques To Coordinate Activities Of The Participating Engineering Technical Teams. 
The designs of the metallic structures were completed four to six weeks later than planned, effectively stretching out the program during the first and second quarters of 1993. Expedited delivery of the metallic hardware was required for schedule recovery.

Delays in the delivery and the quantities of ceramic blades and nozzles received required very aggressive, manpower-intensive efforts in component and engine testing during the third and fourth quarters to keep the program on schedule.

Engine testing was initiated in August, 1993 with the first ceramic blade equipped engine test proving unsuccessful. Engine testing continued at an aggressive rate during September, October, and November. To remain on schedule, the test bed engine was run 18 hours per day, 7 days per week during the month of November.

The 100 hour, 300 cycle ceramic nozzle equipped engine test was successfully completed. However, the planned second ceramic blade equipped engine test resulted in failure of the blades.

At the end of 1993, the program costs were below plan. Engine testing was curtailed as a result of the second unsuccessful ceramic blade equipped engine test. The schedule shown in Figure 31 reflects the planned and completed 1993 tasks. All major planned milestones were successfully accomplished, except the ceramic blade equipped engine testing and the ceramic blade/ceramic nozzle engine test. At the conclusion of 1993, investigation of the failures of the ceramic blades during engine testing was nearing completion and a preliminary plan for ceramic nozzle testing was in place.

In support of ceramic component design, fabrication and testing efforts continued with the enhancement and refinement of several critical ceramic technologies, including design for impact resistance, contact stress design, oxidation and corrosion testing and modeling, proof test life prediction methods, and NDE reliability.

The preliminary schedule for the 1994 tasks is shown in Figure 32.

During 1993 the following administrative activities were completed:

- Six Bimonthly Technical Narrative Reports were published

- Five Review/Planning Meetings were held with DOE and NASA representatives

- A technical paper summarizing the AlliedSignal 1992 ATTAP efforts was submitted to the Society of Automotive Engineers (SAE) for publication in the Proceedings of the October, 1992 Contractors' Coordination Meeting held in Dearborn, MI

- The Turbine Stage Component Design Review was presented to DOE and NASA representatives

- The 1992 ATTAP Annual Report was approved by NASA and published 


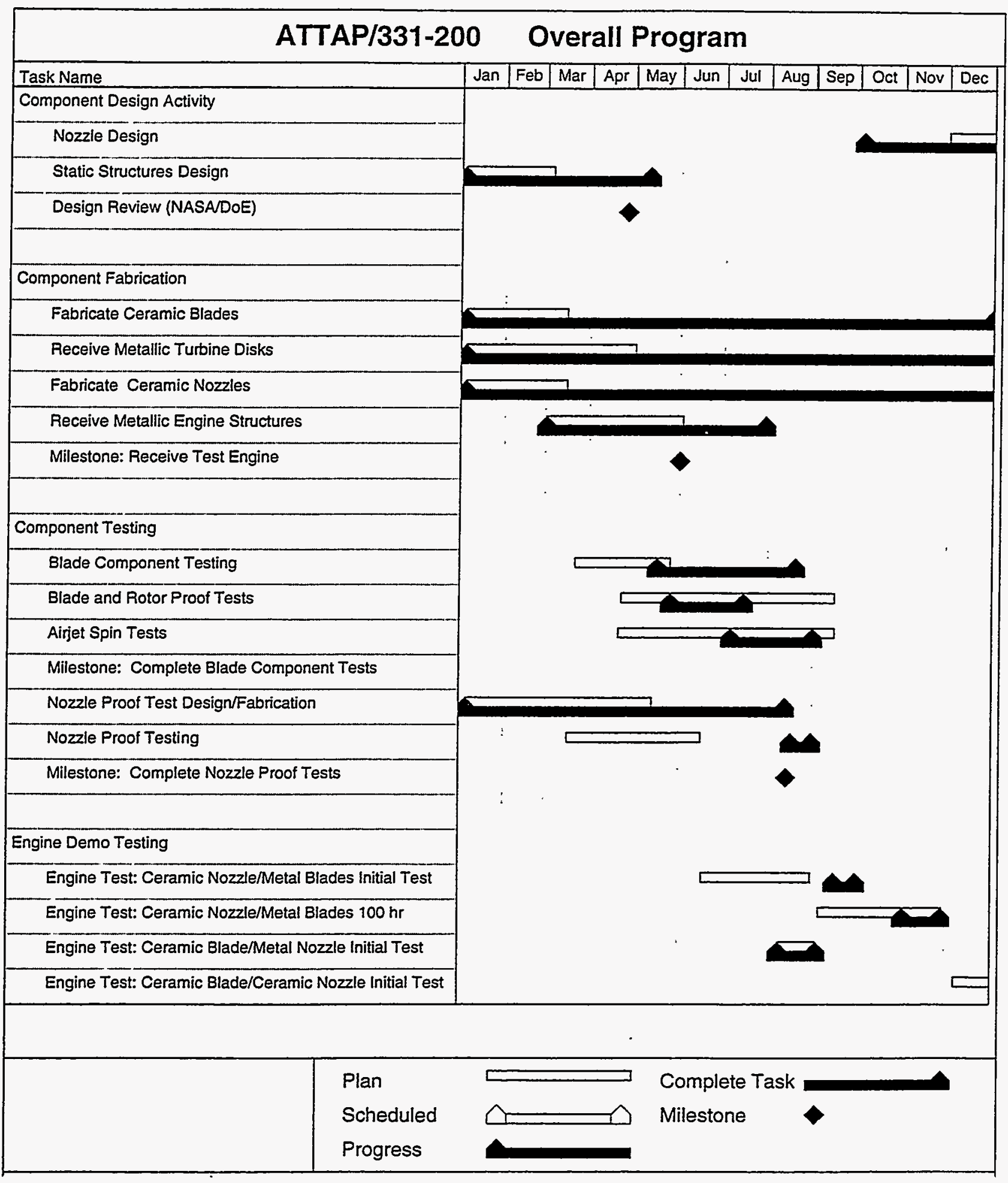

GB12089-31

Figure 31. 1993 ATTAP/331-200 Ceramic Turbine Engine Demonstration Program Schedule Shows Tasks Planned And Completed. 


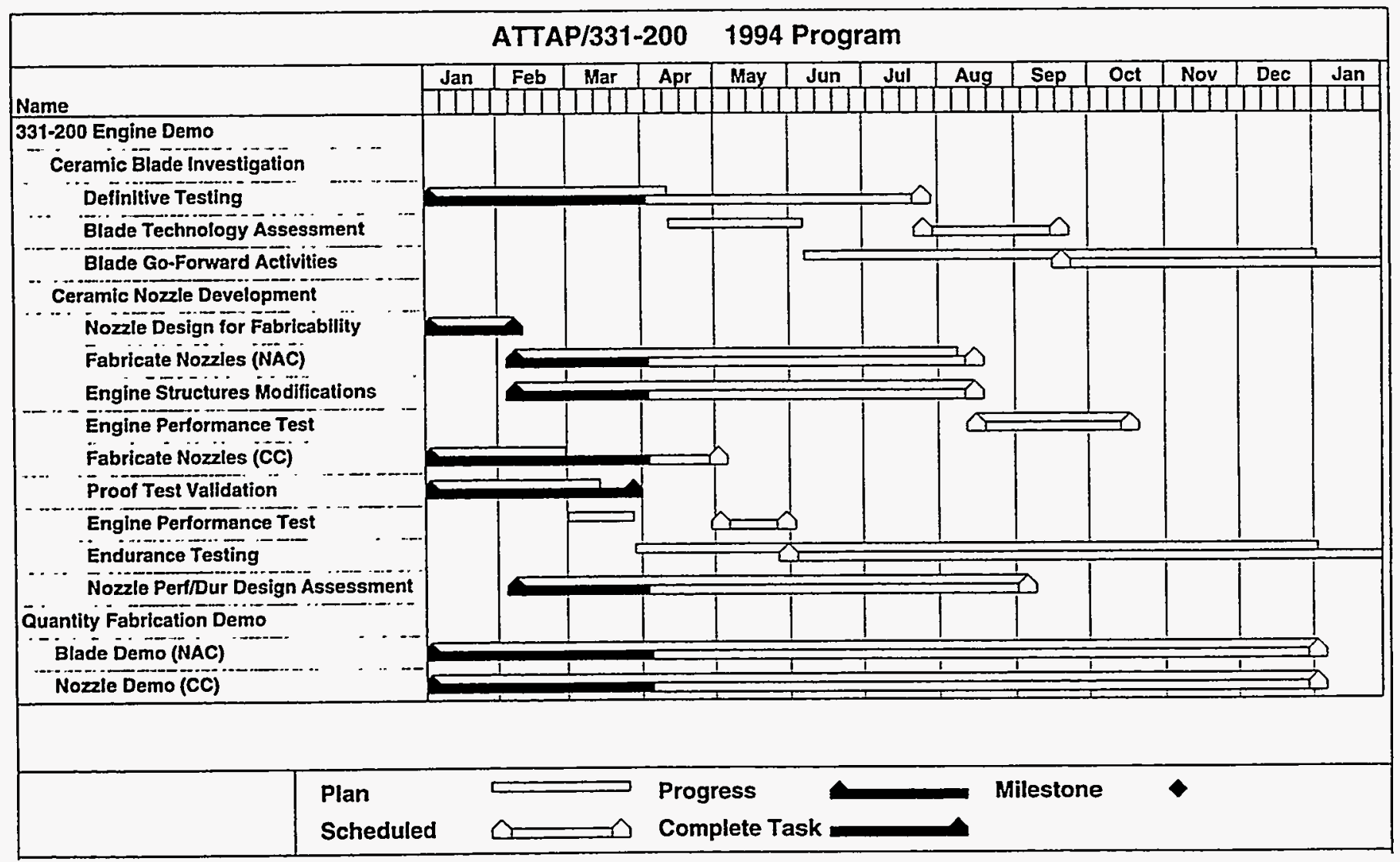

GB12026-75

Figure 32. Preliminary 1994 ATTAP/331-200 Ceramic Turbine Engine Demonstration Program Schedule.

- A paper titled "Ceramic Gas Turbine Technology Development and Application" by J.R. Smyth, R.E. Morey, and R.W. Schultze of AlliedSignal Engines summarizing 1992 ATTAP program results was presented at the 38th International Gas Turbine and Aeroengine Congress and Exposition sponsored by the American Society for Mechanical Engineers (ASME), held in Cincinnati, $\mathrm{OH}$ in May, 1993

- AlliedSignal Engines personnel made a presentation on the 1993 ATTAP/331-200 technical progress at the DOE Contractors' Coordination Meeting, held in Detroit, MI in October, 1993

- A Draft 1994 ATTAP Technical Work Plan was developed in conjunction with NASA

- A draft ASME paper on the 1993 ATTAP/331-200 technical progress was submitted for NASA review

- Statements of Work (SOWs) for the Ceramic Nozzle and Ceramic Blade Quantity Fabrication Demonstrations at AlliedSignal Ceramic Components and Norton Advanced Ceramics, respectively, were issued. 
Public reporting burden for this collection of information is estimated to average 1 hour per response, including the time for reviewing instructions, searching existing data sources, gathering and

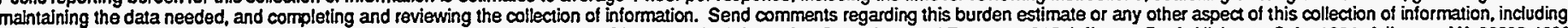

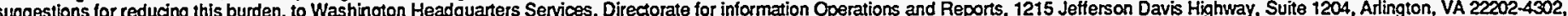
and to the Office of Management and Budget, Paperwork Reduction Project (0704-0188), Washington, DC 20503.

1. AGENCY USE ONLY (Leave blank)

\section{REPORT DATE}

July 1994
3. REPORT TYPE AND DATES COVERED

Contractor Report

\section{TITLE AND SUBTITLE}

Advanced Turbine Technology Application Applications Project (ATTAP) 1993 Annual Report

\section{FUNDING NUMBERS}

WU-778-32-21

DEN3-335

\section{AUTHOR(S)}

Engineering Staff of AlliedSignal Engines

7. PERFORMING ORGANIZATION NAME(S) AND ADDRESS(ES)

AlliedSignal Engines

2739 East Washington Street

P.O. Box 52181

Phoenix, AZ 85072-2181

9. SPONSORING/MONITORING AGENCY NAME(S) AND ADDRESS(ES)

National Aeronautics and Space Administration

8. PERFORMING ORGANIZATION REPORT NUMBER

E9171

31-12089

Lewis Research Center

Cleveland, OH 44135-3191

\section{SUPPLEMENTARY NOTES}

Project Manager, Thomas N. Strom, Advanced Propulsion Applications Office, NASA Lewis Research Center, organization code $2701,(216)$ 433-3408.

12a. DISTRIBUTION/AVAILABILJTY STATEMENT

Unclassified - Unlimited

Subject Category 85

12b. DISTRIBUTION CODE

DOE Category UC-96

13. ABSTRACT (Maximum 200 words)

Reports technical effort by AlliedSignal Engines in sixth year of DOE/NASA funded project. Topics include: gas turbine engine design modifications of production APU to incorporate ceramic components; fabrication and processing of silicon nitride blades and nozzles; component and engine testing; and refinement and development of critical ceramics technologies, including: hot corrosion testing and environmental life predictive model; advanced NDE methods for internal flaws in ceramic components; and improved carbon pulverization modeling during impact. ATTAP project is oriented toward developing high-risk technology of ceramic structural component design and fabrication to carry forward to commercial production by "bridging the gap" between structural ceramics in the laboratory and near-term commercial heat engine application. Current ATTAP project goal is to support accelerated commercialization of advanced, hightemperature engines for hybrid vehicles and other applications. Project objectives are to provide essential and substantial early field experience demonstrating ceramic component reliability and durability in modified, available, gas turbine engine applications; and to scale-up and improve manufacturing processes of ceramic turbine engine components and demonstrate application of these processes in the production environment.

14. SUBJECT TERMS

Ceramic-engine; Ceramic-technology

15. NUMBER OF PAGES

53

16. PRICE CODE

$\mathrm{AO4}$

\section{SECURITY CLASSIFICATION OF REPORT}

Unclassified

NSN 7540-01-280-5500
18. SECURITY CLASSIFICATION OF THIS PAGE

Unclassified
19. SECURITY CLASSIFICATION OF ABSTRACT

Unclassified
20. LIMITATION OF ABSTRACT

Standard Form 298 (Rev. 2-89)

Prescribed by ANSI Std. Z39-18 